Portland State University

PDXScholar

\title{
An exploration into aspects of broken color as exemplified in the works of the Impressionists and Neo-Impressionists and the application of these theories within painting experiences of the adolescent student
}

Frank Edwin Handy

Portland State University

Follow this and additional works at: https://pdxscholar.library.pdx.edu/open_access_etds Let us know how access to this document benefits you.

\section{Recommended Citation}

Handy, Frank Edwin, "An exploration into aspects of broken color as exemplified in the works of the Impressionists and Neo-Impressionists and the application of these theories within painting experiences of the adolescent student" (1969). Dissertations and Theses. Paper 883.

https://doi.org/10.15760/etd.883

This Thesis is brought to you for free and open access. It has been accepted for inclusion in Dissertations and Theses by an authorized administrator of PDXScholar. Please contact us if we can make this document more accessible: pdxscholar@pdx.edu. 
AN ABSTRACT OF THE THESIS OF Frank Edwin Handy for the Master of Science in Teaching in Art presented July 28, 1969.

Title: An Exploration into Aspects of Broken Color as Exemplified in the works of the Impressionists and Neo-Impressionists and the Application of these Theories within Painting Experiences of the Adolescent Student.

APPROVED BY MEMBERS OF THE THESIS COMMITTEE:
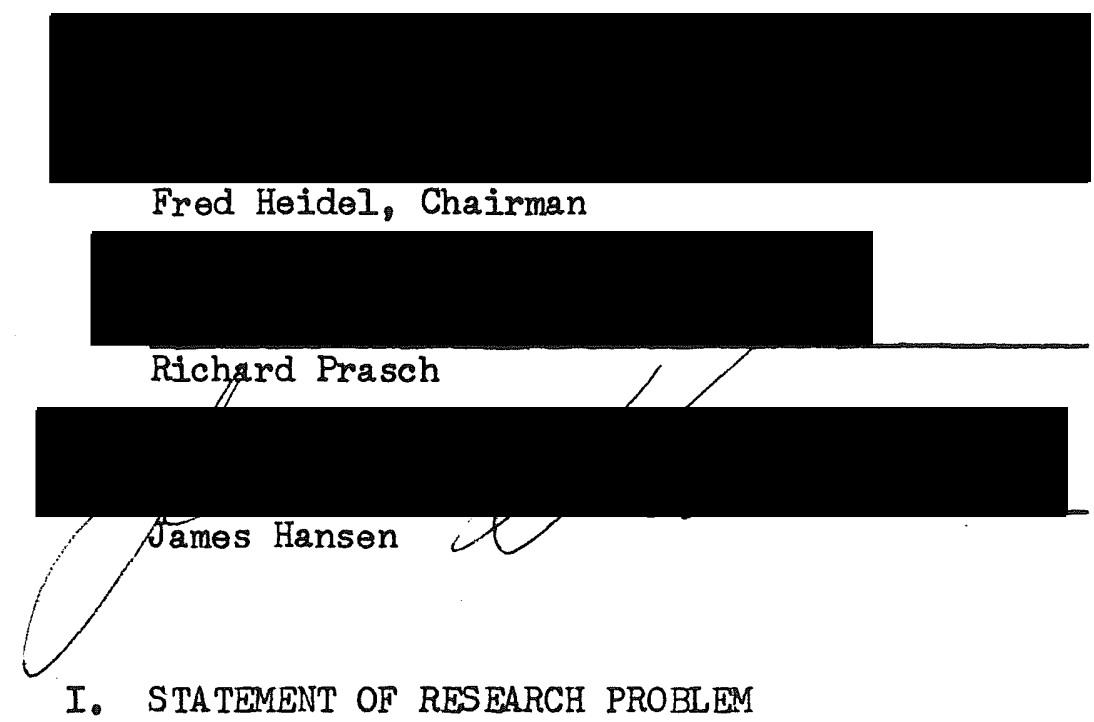

The research was an exploration into the broken color technique within the paintings of the Impressionists and NeoImpressionists and the application of their techniques within the painting experiences of the adolescent student.

\section{RESUME OF THE DATA}

The application of pure pigment directly, without blending, constitutes one of the major aims of the Impressionists and NeoImpressionists. The breaking of color was done in many methods 
by juxtaposition of hues and values in various combinations to give the desired effect; it was applied through a wide range of brush techniques such as comma-shaped, spots, hatchings, and a multitude of undefinable forms.

\section{Historical Data}

The emphasis upon color in painting has a heritage stemming from the city of Venice during the Renaissance. The Venetian artists began what is known today as the painterly direction of painting. Many artists thereafter portrayed this painterly mode such as Caravaggio, Rubens, Constable, and Delacroix. It was, however, during the latter half of the ninteenth century in France that the painterly style reached new heights through the art of the Impressionists. The Impressionists sought to capture the momentary effect of light upon their canvases through many diverse methods of broken color. The Neo-Impressionists felt Impressionism was too unstructured; therefore, they based their method on a scientific approach. Colors were broken into small dots and placed contiguous to one another. Through optical fusion, these dots would fuse into a new and more vibrant hue.

\section{Painting Data}

Data was gained from the involvement into actual painting where the broken color techniques were explored. Some of the factors are that media having a rapid drying quality (such as acrylics or casein) are superior to the slower drying oils; that the various methods of brush strokes used in the application of pigment created a 
varied broken effect; and the use of pure hues aids in the freshness of color passages.

Educational Data

Within art education a knowledge of the aspects of broken color will aid the art educator in presenting a painting program in which the student will become involved in exploring new dimensions in color perception.

\section{DATA OBTAINED}

The data was obtained in three principle ways: the readings relevant to the subject, the involvement into specifically related paintings, and the application of broken color techniques within the adolescent art program.

\section{Readings}

The readings involved the general history of the period, biographies, and texts relating to aspects of color.

\section{Paintings}

Several large paintings were undertaken with specific objectives. Four major paintings were done in the divisionalist method, each with selected subject and light conditions. Others were painted by the direct application of pure pigment with Iandscape and figures as the motif.

\section{Classroom Application}

The techniques of breaking color were presented to several groups 
of adolescent art students. They were encouraged to explore divided color utilizing various media.

\section{SUMMARY}

Research in the broken color technique should create a greater visual awareness of the richness of color. Through the juxtaposition of color the eye would be put to work mixing colors; the observer, therefore, will take a more active role in the perception of all images on the retina of the eye.

The emphasis upon color in painting had a long heritage; it was fully exposed in the broken color style of the Impressionists. NeoImpressionism also added new vistas in the perception of color. This period of painting contributed greatly to the contemporary arts. Therefore, it is an important era to be explored by art students today to develop more insight into the nature of color within painting. 
AN EXPLORATION INTO ASPECTS OF BROKEN COLOR AS

EXEMPLIFIED IN THE WORKS OF THE IMPRESSIONISTS AND NEO-

IMPRESSIONISTS AND THE APPLICATION OF THESE THEORIES WITHIN

PAINTING EXPERIENCES OF THE ADOLESCENT STUDENT

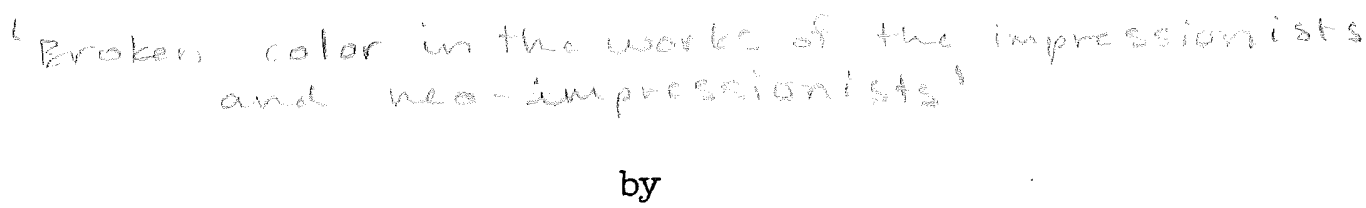

FRANK EDWIN HANDY

A thesis submitted in partial fulfillment of the requirements for the degree of

MASTER OF SCIENCE IN TEACHING

in

ART

Portland State University

1969 
TO THE OFFICE OF GRADUATE STUDIES:

The members of the Committee approve the thesis of

Frank Edwin Handy presented July 28, 1969.

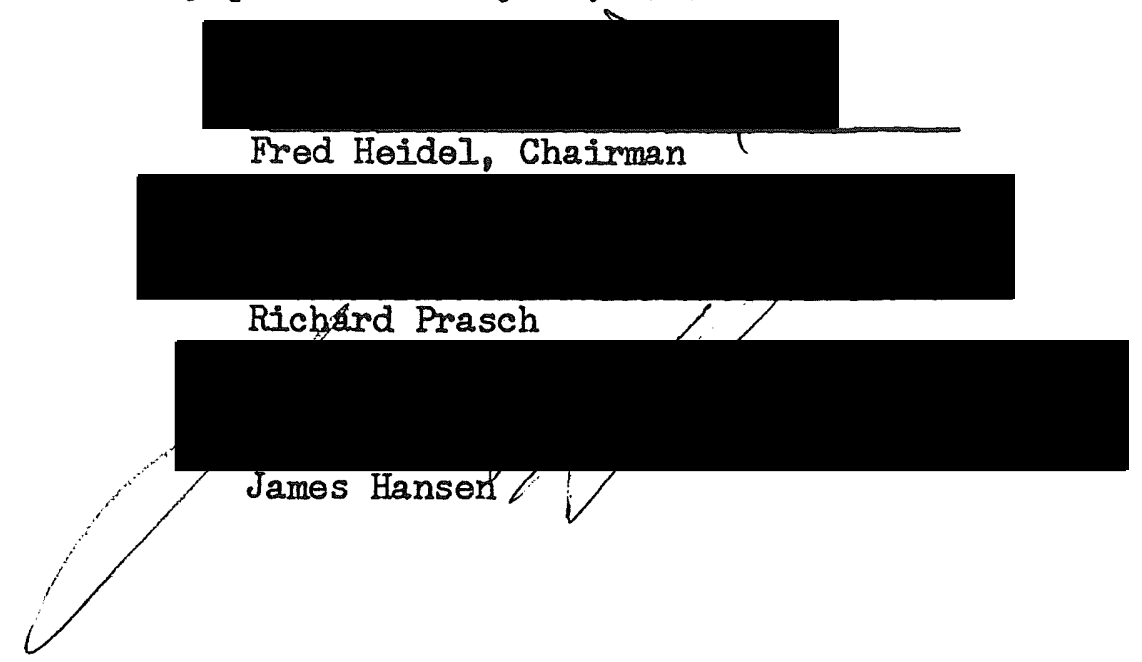

APPROVED:

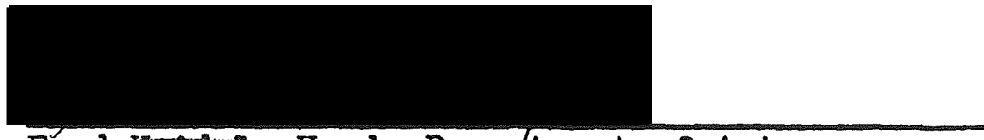

Fred Heidel, Head, Department of Art (2)

4 David $R$. MaIcolm, Doan of Graduate Studies

August 8, 1969 
TABLE OF CONTENTS

PAGE

IIST OF FIGURES . . . . . . . . . . . . . . .

CHAPTER

I INTRODUCTION . . . . . . . . .... 1

Broken Color ................ 1

Research into Aspects of Broken Color ... 2

II THE NATURE OF COLOR ............ 4

Color ..................... 5

Color Mixture ............... 8

Color Notation............... 10

Broken Color and Perception ...... 12

III COLOR HERITAGE . . . . . . . . . 15

Historical Contributions . . . . . . 16

IV TMPRESSIONISM AND BROKEN COLOR . . . . . . 21

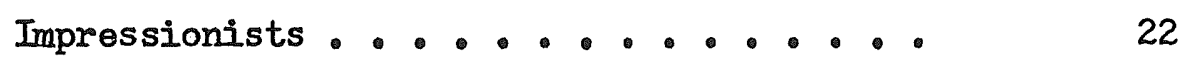

- Broken Color of the Impressionists . . . 22

V NEO-IMPRESSIONISM AND BROKEN COLOR . . . . 27

Neo-Impressionists ........ 28

Broken Color of the Neo-Impressionists . . . 28

VI STUDIES OF DIVISIONAIISM . . . . . . . 34

Description of Problem ............ 34 
CHAPTER

Technical Aspects ..............

Four Studies of Pointilism . . . . . . .

Summary ......... . . . . . . .

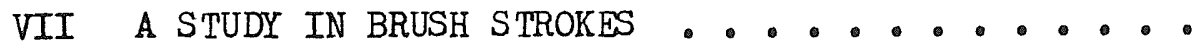

VIII LANDSCAPE STUDIES ................

Technical Aspects ............

Paintings ...................

IX FIGURE STUDIES...$\cdot \cdot \cdot \cdot \cdot \cdot \cdot \cdot \cdot \cdot \cdot \cdot \cdot \cdot \cdot$

Paintings ...................

Summary ...................

X ADOLESCENT PAINTING ..............

The Adolescent Art Student . . . . . .

The Painting Program .......... .

The Subject of the Paintings .......

Classroom Media .............

XI SUMMARY AND CONCLUSIONS ..$\cdot \cdot \cdot \cdot \cdot \cdot \cdot \cdot \cdot \cdot \cdot$

Summary . . . . . . . . . . . . •

Conclusions ................ 
LIST OF FIGURES

FIGURE

PAGE

1 The Radiant Spectrum. ............. 7

2 Impressionist Sunrise ............. 21

3. Impressionist Palette........... 25

4 La Grande Jatte......................... 27

5 Study for "Une Baignade" .......... 30

6 Ink Pointilism Study............ 36

7 Close-up of Ink Study . . . . . . . . 37

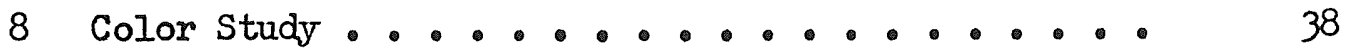

9 Close-up of Color Study ........... 38

10 Still Life with Bucket ........... 39

11 Close-up of Still Life with Bucket ....... 40

12 Evening Harbor. ..................... 41

13 Topless Dancer ................. 42

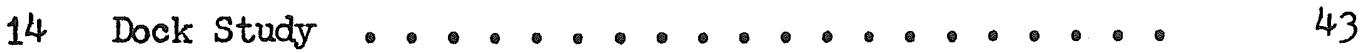

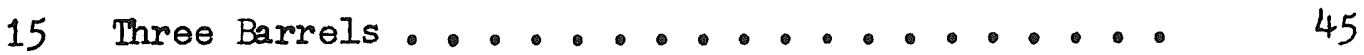

16 Print of Country Road ............... 47

17 Country Road ......................... 47

18 Close-up print of Country Road ........ 48

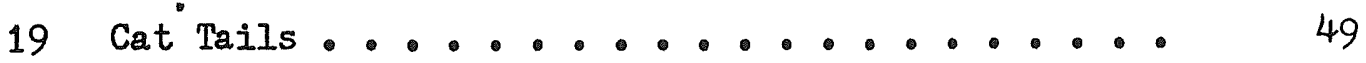

20 Print of Cat Tails . . . . . . . 50

21 Print of Rock Quarry ......... 50

22 Rock Quarry .............. 51

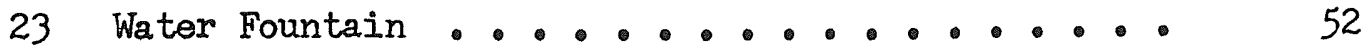


24 Park Steps ...................

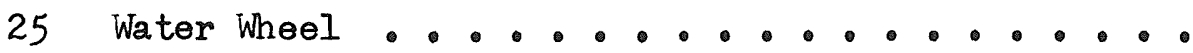

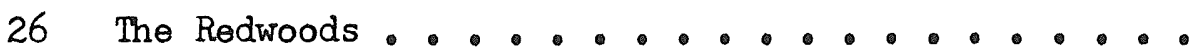

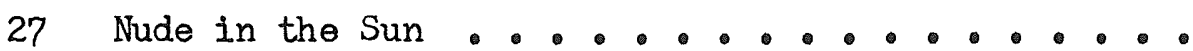

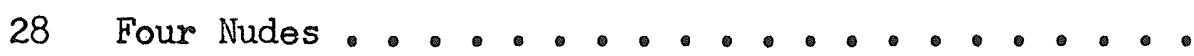

29 Close-up section of Four Nudes .........

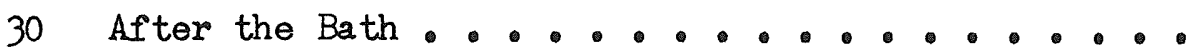

31 My Son .....................

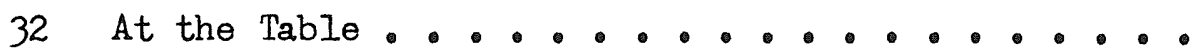

61

33 Painting Supplies ................... 64

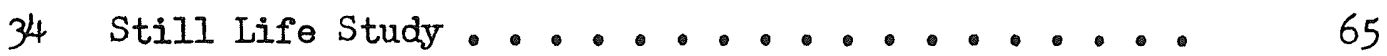

35 Landscape Study .................... 66

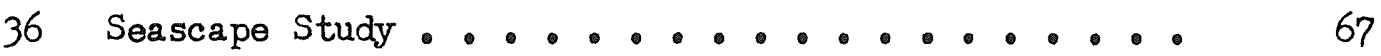

37 Application of Paste . . . . . . . . . 67

38 Student Painting Display . . . . . . . . 71

39 Example of Broken Color ......... 72 
CHAPTER I

\section{INTRODUCTION}

Impressionism was one of the most revolutionary styles of painting within the history of painting. This style evolved in the latter half of the nineteenth century in France. The painting method of the impressionist artists was to paint alla prima (at once), by applying the right colors directly to the canvas without blending. All they wanted was a general effect, an "impression" of what they actually saw. The Neo-Impressionist, Georges Seurat, felt the Impressionist's fluid style had a "sketchiness" quality and he devised a system of juxtaposition of small dots on the surface of the canvas to make Impressionism solid and durable.

\section{BROKEN COLOR}

Due to the separation of vivid strokes of pigment, this style has come under the general descriptive definition as "broken color" painting. It becomes difficult to accurately describe the broken color style of Impressionism in specific terms. A wide gap exists in the broken color style. There is a gap between artists such as Monet and Degas; a different style from one phase of an artist's career to the next; and even within a single painting the technique may vary. The Impressionists expressed no scientific theory nor signed any manifesto; therefore, it was left to critics, freinds, and historians to 
describe their many faceted broken color style. The Neo-Impressionist's broken color style has been described quite accurately due to the nature of their technique. They practiced a scientific study of color and the systematic division of pigment which were practiced instinctively by the Impressionists.

\section{RESEARCH INTO ASPECTS OF BROKEN COLOR}

An orderly sequence must be undertaken to explore many ramifications of the "broken color" style of the Impressionists and Neo-Impressionists and to apply the research within art education. Three major divisions have been included within the scope of this paper: first, the gathering of written information; second, the exploring through the involvement into paintings; and lastly, the applying of the aspects of broken color within art education.

Research Through Written Material

Nuch can be learned from the heritage of the artists who have contributed to modern painting. Authors such as John Rewald, William Homer, Faber Birren, and a wealth of others have contributed much to the understanding of the history of the Impressionist and Neo-Impressionist era. The first part of this paper concerns itself with the research pertinent to the broken color style.

\section{Research Through Painting}

The involvement into painting related to the broken color style and the descriptive analysis of these paintings will be explored within the second section of this paper starting on Chapter III. 
Application within Art Education

The last part will be the application of the research within art education aimed at painting experiences which exemplify the beauty and richness of pigment applied to canvas with considerable freedom. 
CHAPTER II

THE NATURE OF COLOR

The nature of color was never so closely observed as in the latter half of the nineteenth century in France. At no other time prior to the twentieth century had color dominated painting to such an extent as did the art of the Impressionists and Neo-Impressionists. "One of the Impressionists" chief aims was to record the appearance of their subjects as conditioned by the light falling on it without any preconditions of any kind."1 Nature to the Impressionists was seen chiefly as patches of colored light. In documenting the aspects of colored light upon their canvases, the Impressionists used many diverse methods of brush strokes to break color to give the shimmering effect of light such as comma-shaped, short dashes, spots, hatching, and a multitude of other undefinable forms. Impressionist paintings, therefore, have a sketchiness, a generally unstructured surface which were painted in a broken color style which to the Neo-Impressionist lacked intellectual order.

Georges Seurat, the founder of Neo-Impressionism, wanted to give a systematic scientific basis to painting based on physicists theories of light. He devised a method of applying brush strokes of small dots of multi-colored hues placed contiguous to one another to create the

1William Homer, Seurat and the Science of Painting, (Cambridge, Massachusetts: M.I.T. Press, 1964), p. 56. 
effect of light through full or often partial optical mixture depending on the distance away from the surface it is viewed.

Light, therefore, became the most important element of the Impressionist and Neo-Impressionist painting. All forms bathed in light and atmosphere were recorded in many varied ways and must be understood through a general understanding as to the nature of color itself. An accurate explanation of color has of yet to be resolved, there is however, a generally accepted color theory.

\section{COLOR}

The sun in the heavens is the source of all light and color apart from the artificial illumination such as electric or candle light. "The surface of the sun appears to be in a state of violent molecular excitement, and this excitement is communicated to the ether which permeates all space."2 From the ether comes forth waves of radiant energy much as rock thrown into water creates waves upon the shore. As these waves enter the earth they are white light. This white light undergoes a transformation, for whatever it touches effects it and turns it into another light. If for example it falls upon the grass of a field or green pigment upon a canvas, it radiates green in all directions due to the molecular or chemical character of the pigment. "A pigment absorbs light of certain wave lengths and reflects light of all other wave lengths." 3 Therefore, we can suggest that

2Roland Rood, Color and Light in Painting, (New Yorks Columbia University Press, 1941), p. 85.

Maitland Graves, The Art of Color and Design. (3rd ed.; York, Pa.: Maple Press Co., 1951), p. 321. 
green grass or pigment is a minature sun radiating green light. To the Impressionist painter a landscape would consist of a multitude of broken hues of radiant energy producing excitation to the retina of the eye which he would record upon the canvas. The eye thus becomes an important element in Impressionism.

An analysis of white light was first accomplished in 1676 by Sir Isaac Newton using a triangular prism. He found that if a beam of sunlight enters through a slit in an opaque screen to strike a prism, the waves are tilted on their axis by striking two sides of the prism and then are dispersed in what we call a spectrum. 4 Figure one explains the limits of human vision in the radiant spectrum. These various colors are the results of rays of different character acting on the retina of the eye.

When the waves constituting the rays are short, they act in such a manner that the retina telegraphs certain signs to the brain and hence to the mind, and we experience the sensation of violet. When the waves are slightly longer, we experience blue and so on. The longest rays produce reds.5

An important factor in the optics of viewing broken color within painting is an understanding of how the eye functions in perceiving the multitude of broken hues which were important to the Impressionists and particularly the Neo-Impressionism of Seurat. The retina of the eye contains two distinct types of cells named

4 The spectrum hues were selected by the Impressionists and NeoImpressionists to be placed upon their palettes in their search for light in their paintings.

50lor Digest, (Brooklyn, New Yorks Higgins Ink Co., 1965), p. 15. 
according to their supposed shapes, rods and cones. Rods are thought of as light and dark sensitive and cones as color sensitive.

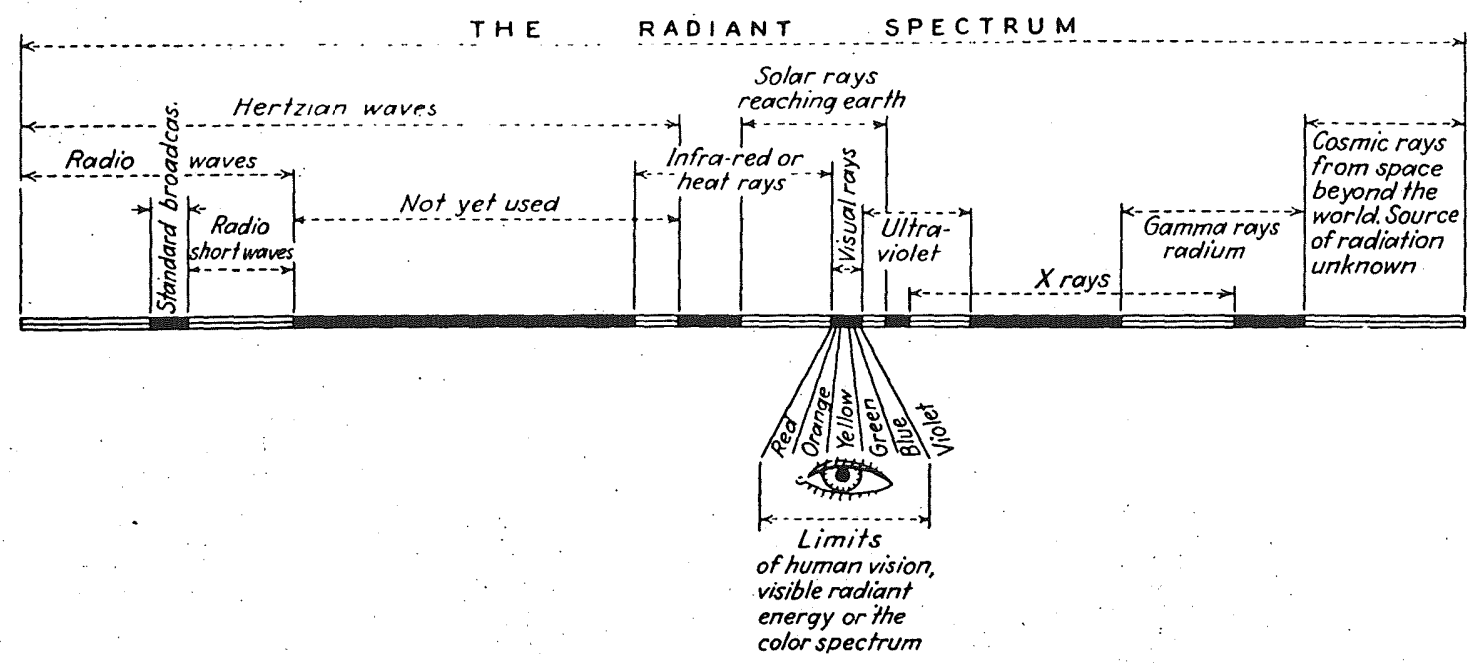

Figure 1. The Radiant Spectrum. 6

The retinal cells are supposed to have different chemicals in them which are affected by the various wavelengths of light. The quantities of the chemicals are minute. The action is instantaneous with the focusing of the eye and nature is constantly renewing the chemicals to maintain the normal balance for the individual whatever it may be. We point out that the balance is probably different within limits for each individual. When a particular chemical or chemicals are affected by the action of light, the remaining chemicals or chemical give us impressions of color.?

The lens of the eye has much to do with visual perception of the broken areas of a surface of an Impressionist or Neo-

6raves, The Art of Color and Design, p. 318.

7 Color Digest, p. 6 . 
Impressionist painting. As one views a broken colored surface, the lens of the eye as it alternately contracts and expands in an effort to focus two colors simultaneously causes sensation of vibratory movement. Advancing and receding colors may be explained by the lens also.

Because red is only slightly refracted by the lens of the eye, it tends to focus at a point behind the retina. Hence, to see it clearly the lens grows convex, enlarging the red image and pulling it nearer. In reverse fashion, blue tends to focus at a point in front of the retina, the lens flattens out, pushing the blue image back and makes it appear farther away. 8

An understanding of the workings of the eye will aid painters in their work to present rich vibrant surfaces on their convases. When all hues are carefully blended or modeled within a painting, the observer may take a passive role in perception. If, however, the surface is broken, the observer must take an active role and visually involves himself in the painting.

\section{COLOR MIXTURE}

An artist's palette usually relies on the principle of subtractive mixture of pigments. Many Impressionists explored many aspects of broken color and especially the Neo-Impressionists. Each group relied heavily on additive mixture of color due to optical mixture or optical fusion.

\section{Subtractive Mixture}

When colors are mixed upon the artist's palette or at times on

8Faber Birren, History of Color in Painting, (New York: Reinhold, 1965), p. 130 . 
the surface of a painting, we call it subtractive mixture because the pigment absorbs or subtracts light and reflects the remaining light to the retina. The primary colors in the subtractive process are red, yellow, and blue. According to this system, the mixture of red and yellow produce orange; yellow and blue together produce green; blue and red produce violet. If all three primaries are mixed with each other, the result will be an almost neutral black due to the pigment subtracting most of the light rays.

\section{Additive Mixture}

There are several techniques involved in additive mixture, the most common being the superimposition of beams of light projected through colored filters. The additive primaries are red, green and blue-violet (light). Red and green produce yellow; green and blueviolet produce blue-green; and red and blue-violet produce purple. When all three primaries are mixed, the result is white light.

\section{Optical Mixture}

Optical Mixture of Pigment. When colors are applied to a canvas in a broken color technique by juxtaposition of pigments in spots, hatchings, and other methods to break colors, they will fuse into a third color depending on how far one steps away. When such a technique is used, additive mixture is supposed to take place. The pigments placed contiguously will be guided by principles of additive, not subtractive mixture. The theory of optical fusion of pigment has been supported by many writers on the subject of color.

The effects produced by additively mixing chromatic light 
beams reflected from opaque paints (chromatic reflectors) are essentially identical with those effects produced by additively mixing chromatic light beams transmitted by transparent filters (chromatic filters).9

Optical Mixture in Painting. "Georges Seurat shared Cézanne's aim to make Impressionism solid and durable, but he went about it differently."10 Seurat believed art must be based on a system. An important element of that system was "optical fusion". Tiny dots of brilliant color were supposed to merge in the beholders eye and produce intermediary tints of more luminous hues than those obtained from pigments mixed on the palette.

More emphasis will be placed on the importance of optical mixture within Chapter $V$, Neo-Impressionism And Broken Color, due to the importance of visual fusion of divided color within their theories.

\section{COLOR NOTATION}

In discussing broken color in painting it is essential to adopt a uniform system of color notation and terminology. The idea of charting colors was first adrocated by Sir Isaac Newton in 1666. He suggested the red and violet ends of the visual spectrum are brought together and joined into a chromatic circle. "Since then numerous scientists and artists have studied the matter of color circles and have come to various conclusions."11 Systems based on identification p. 29.

9Maitland Graves, Color Fundamentals, (New Yorks McGraw, 1952), p. 505 .

10H. W. Jansen, History of Art, (New York: Abrams Inc., 1963), p. 17 .

11Faber Birren, Creative Color, (New York: Reinhold, 1961), 
by letter or number create difficulties for easy analyzing of color such as Ostwald or Munsell color circles. Each color circle is based upon a sequence of pure hues arranged about the arc; however, the amount of hues vary with each system.

Traditional in the field of art is a color circle based on red, yellow, and blue. "The first concept of red, yellow, and blue as primaries in pigments dates to about 1731 and is credited to $\mathrm{J} . \mathrm{C}$. Blon."12 He did not visualize the hues in the circular form and it was left to Moses Harris, an Englishman, in 1766. Thereafter, the red, yellow and blue circle became the common working tool of the artist.

As one explores aspects of broken color within specific paintings, color must be explained as clearly and simply as possible. Authors such as Arthur Pope, 13 Maitland Graves, 14 William Homer, 15 and others have suggested color as having dimensions for easy identification. The dimensions of color are; hue, the name of a specific color such as red or blue; value, the degree of lightness or darkness of a color intensity, the strength or purity of a color. An addition of white creates a tint, black a shade, and both a tone.

12M. E. Chevreul, The Principles of Harmony and Contrast of Colors, introduction and notes by Faber Birren, (New York: Reinhold, 1967), p. 95.

13Arthur Pope, The Language of Drawing and Painting, (Cambridge, Mass.: Harvard University Press, 1949), chapter I.

14 Graves, Art of Color and Design, p. 324 .

15Homer, Seurat and the Science of Painting, p. 8. 
Another dimension suggested by Ogden Rood"16 is Iuster. "Luster means scintillation, or glitter, or sparkle, or glimmer, or glow."17 Rood explained that luster may be confused with intensity or chroma. An example of luster may be found in nature such as waves dancing upon the surface of a pond or sunlight shimmering from a grassy field. The Impressionists used many diverse methods of breaking color to capture the effect of shimmering light upon their canvases.

Because broken color is so universally present in nature and is always producing luster, we accept the luster as being a part of the color of the object itself, and fail to recognize the ever-present broken color producing it. 18

\section{BROKEN COLOR AND PERCEPTION}

The perception of various hues of different degrees of chroma and value placed contiguous to one another has been observed throughout history. At no other time has the visual phenomena been so closely studied as in the last century. Writers on color such as Ogden Rood, Michel Eugéne Cherreul, Ralph Fabri, Faber Birren, Josef Albers, Johannes Itten and others have placed a wealth of information before the public. The author having the greatest impact upon the perception or visual awareness of the artists of the Impressionist and Neo-Impressionist period was Michel Eugene Cherreul in his book, The Principles of Harmony and Contrast of Colors, that came out in

${ }^{16}$ Ogden Rood (1831-1902) was an American who taught at Columbia where he did extensive research and publication and was important to the development of Neo-Impressionism.

17 Rood, Color and Light in Painting, p. 88.

${ }^{18}$ Ibid. p. 121. 
its original French edition in 1839.

Some of the artists who were painting during the 103-year life span of Cherreul were Delacroix, Pissarro, Cézanne, Monet, Renoir, Van Gogh, Seurat, and Signac.

Camille Pissarro was perhaps the most ardent admirer of

Chevreul and the Impressionist who was most concerned with the new scientific attitude toward color. An avid reader of Chevreul, he did his best to convert Cézanne, Monet, Renoir, Van Gogh, and Signac to the new color order. ${ }^{19}$

Pissarro along with other important artist such as Van Gogh, Gauguin, and Cézanne went through a phase of pointilism conforming to what Chevreul termed mixed contrast. Seurat, Signac and later Henri Cross continued research into the juxtaposition of pigment upon their canvases.

Chevreul at an early date recognized color perception was far from static and the eye modified what it perceived. He discovered that the apparent intensity of color did not depend as much on the inherent color of pigment as it did on the neighboring hue. From this he formulated the law of simultaneous contrast which states that when two colored objects are observed together, the color of each will be influenced by the complementary of its neighbor. This law applies equally to value: when two objects of different value are juxtaposed, the lighter one will become lighter and the darker even more dark in appearanc $\theta$.

After Chevreul, the French Impressionists and Neo-Impressionists seized upon the results of his research into color perception. Faber

${ }^{19}$ Chevreul, Principles of Harmony and Contrast of Colors, p. 35. 
Birren made this comment in his notes in Chevreul's book. The Principles

\section{of Harmony and Contrast of Colors.}

Chevreul laid the foundations for these movements in art. Where formerly a painting was to be accepted as something fixed and permanent - to be seen largely as a static image on the retina of the eye - now through contrast of color, through new techniques of color application, the eye would be put to work mixing colors; scintillating beauty would be seen which really did not exist on the canvas, but in the eye of the beholder. 20

20 Ibid., p. 69. 


\section{CHAPTER III}

\section{COLOR HERITAGE}

A generalization has often been made that within the history of painting there are two general styles, the painterly with emphasis on color and linear with emphasis on line. The Impressionists and Neo-Impressionists would obviously be placed in the painterly style and therefore would draw heavily from the heritage of those artists who employed the colorist mode of painting.

An inquiry into the characteristics of the painterly style is important due to the contributions of those artists who were later to inspire the manner of painting of the late nineteenth century. The painterly artist is content to give an impression of what is seen and may paint what he sees and not what he knows. Outlines are often blurred, or lost entirely, since it is not by its outlines that an object is defined but by value differences. Details, consequently, are obsure; there is a certain haziness of focus; all of which is typical of painterly vision. Texture of pigment may be heavily applied in an impasto manner creating a rich broken surface. Colors are not confined to a line-like boundary and merge into one another. These general characteristics were developed by artists primarily from the fifteenth century to Impressionism. The Impressionist artist will explore many ramifications of these generalizations. The color heritage must be studied in order to explore the implications of broken color. 


\section{HISTORICAL CONTRIBUTIONS}

The artists of each period of art contributed to the painterly qualities which were paramount in the broken color style of the Impressionists and Neo-Impressionists. The traditional and the contemporary paintings of that period were hung in the Paris Salon and were used as an inspiration to many artists of the nineteenth century. A selection of a few painters will be chosen to illustrate the painterly direction in the visual arts in which the broken color style of Impressionism and Neo-Impressionism evolved.

\section{Traditional Heritage}

The traditional painting heritage of the artists during the Renaissance has set the pattern for painting modes towards color or linear painting. Where Florence and Rome were oriented toward ancient Etruscan and Roman monuments which were still visually about, the Venetian artist drew his inspiration from the east, meaning Byzantium. The rich broken hues of colored fabries gave the Venetian culture ideas of color and surface decoration. Within Venetian painting, line is partially done away with and more emphasis placed upon the plastic qualities of color. Color becomes an important element within the total design of the paintings; not just a colored drawing. A hue may have a fluid quality, it may change from blue to green in one object and may continue beyond the boundary of that object. The painterly heritage of painting thus had its birth and will grow to maturity in Impressionism and Neo-Impressionism. 
Traditional Artist Exemplifying Painterly Qualities

Italy. Venice found its greatest painting expression in the paintings of the Bellinis, of Giorgione, and of Titian. This may have been the greatest school of color Europe has ever produced. The Italian Baroque artist, Caravaggio, painted objects closely about him with precision of light, texture, and color.

Spain. The three artists who employ degrees of painterly style are El Greco, Velazquez, and Goya. El Greco developed a unique and origional expression with color. He held color to be more important than drawing which is understandable since he was trained in Venice. 21 Velazquez richness in style seemed to foreshadow Impressionism. In his painting, Maids of Honor, details were painted by juxtaposition of different pigment in dashing thick and thin strokes.22 Goya searched for a way of painting that would present an image with inmediacy of instant vision. Goya complained, "Where does one see lines in nature? I only see forms, forms that are lighted and forms that are not."23 The directness and richness of Spanish color will later be of influence in the impressionist paintings of Manet in his early style.

Low Countries, Two artists of the low countries who displayed painterly characteristics within their painting were Rembrandt and Rubens. Rembrandt created very astonishing luminous effects with

${ }^{21}$ Birren, History of Color in Painting, p. 241.

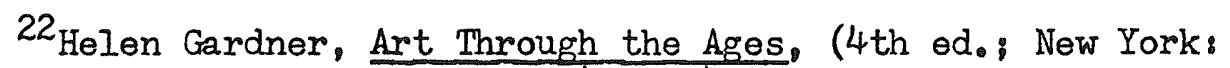
Harcourt, Brace and Company, 1959), p. 418.

23 John Canaday, Mainstreams of Modern Art, (New Yorks Holt, Rinehart and Winston, 1965), p. 85. 
a limited palette of but six hues. 24 Light and shadow were the most important elements of his painting style. The Flemish artist Rubens spent some eight years in Italy under the influence of Venetian colorists. He developed a broader and bolder style than had been previously attempted.

\section{Contemporary Influences}

The direct influences upon the artists destined to become leaders of Impressionism were the scientific inquiry of Chevreul, Rood and others and those artists who exemplified certain painterly characteristics in their paintings. The artists who anticipated the broken color style of the Impressionists were the English painters, Turner and Constable, the great French artist, Delacroix, the bold impulsive colorist Monticelli, and the landscape artists, Boudin and Jongkind.

Turner and Constable. Turner and Constable were extremely strong colorists. Turner was perhaps more spontaneous than the later Impressionists. "He worked with brush, palette knife, fingers, lumps of opaque paint, transparent glazes and varnishes - all to put on canvas, not a method of painting but blinding vision."25 Constable was drawn to landscape painting and recorded nature with pure and broken hues and filled his shadows with complements. In 1824, a painting entitled The Hay Wain was shown in the exhibition of the Salon de Paris where it inspired the great colorist Delacroix. Later in 1871 the

\footnotetext{
24 Birren, History of Color in Painting, p. 261. 25 Ibid., p. 261.
} 
Impressionists Monet and Pissarro were in England where the study of the works of Turner and Constable gave further impetus to the Impressionist evolution which had already begun.

Delacroix. Delacroix took an early interest in color and color theory and was the prophet of color against the linear painter David. The colors seem to be at random about his canvases but they were selected and juxtaposed by no chance but by the theories he so highly developed. He stated, "Color is the merging of reflections."

From Delacroix the impressionists inherited discoveries in the theory of color upon which they enlarged. His technique of applying color in individual strokes was extended to such a point that the surface of some impressionist painting became rough texture of dots and dabs of paint. 26

Barbizon Artists." This was a group of artists who painted from nature in a small village of Barbizon, not far from Paris. These artists, painting in the early years of the nineteenth century, laid a strong foundation for the impressionist painters. The two more important artists of this group were Millet and Carot. Carot's structured style with controlled values was the most influential of the Barbizon artists.

Boudin and Jongkind. The artist Boudin was very important in that he became an early teacher of Monet. He proclaimed the necessity of working with clean colors and exploiting the magic of light. Jongkind, a Dutchman, settled in France where he succeeded in learning to put Iuminosity, fluidity, and glittering movements on canvas. Monet, Boudin, and Jongkind became fast friends, all three fascinated by

26Canaday, Mainstreams of Modern Art, p. 184. 
nature's colorful phenomena.

Summary

The painterly mode of expression had for several centuries foreshadowed the flowering of Impressionism. The soil for the seeds had been prepared by a heritage of creative artists. These seeds will grow to bloom into the most colorful period of modern painting. The use of pure hues, juxtaposed by vivid strokes presented the world some of the most scintillating canvases of any era of modern painting. 


\section{CHAPTER IV}

\section{IMPRESSIONISM AND BROKEN COLOR}

"Impressionism was not a school so much as it was a brotherhood of spirit."27 It was a new attitude toward nature; a new way of seeing nature; a new way of recording nature.

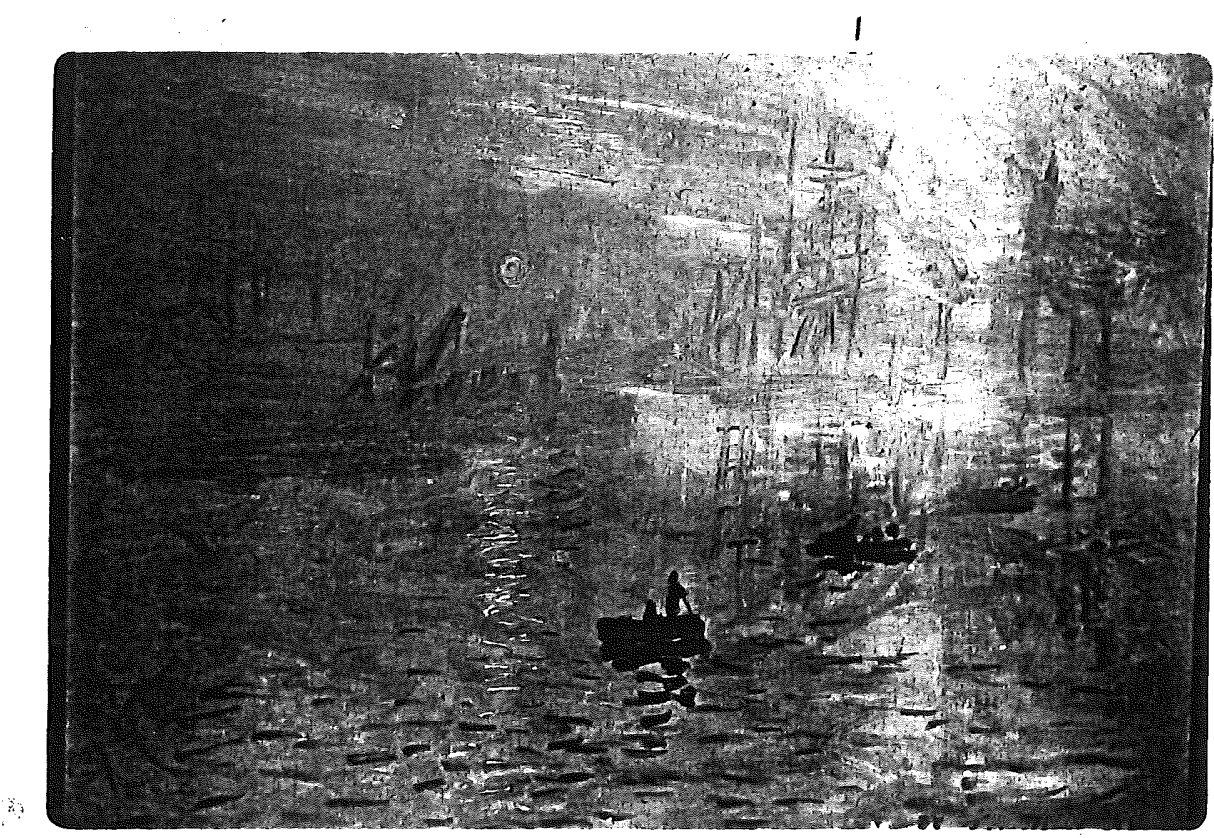

Figure 2. C. Monet, Impression - Sunrise, $173 / 4 \times 215 / 8$ in.

In 1874 a group destined to be the core of this new revolutionary way of thinking met in Paris at the Café Guerbois to organize a society to exhibit their work. The exhibition had hardly opened before the painters were dubbed "impressionists". The name presumably

27 Birren, History of Color in Painting, p. 271. 
was adopted from the title of a picture by Monet in Louis Leroy's review of the exhibition. The name of the painting was Impression - Sunrise (Figure 2). Since Monet was certainly the purest Impressionist of the lot, the identification of the new manner with this particular canvas is entirely just.

\section{IMPRESSIONISTS}

The Impressionist painters were born between 1830 and 1841; Pissarro was the eldest followed by Manet, Degas, Sisley, Monet, Renoir, Bazille, Guillaumin, and Berth Morisot. These painters met in Paris about 1860 with common revolutionary attitudes toward painting. Within the following decade these artists painted in the early exploratory phases of Impressionism. It can be generally stated that from just prior to the first exhibition in 1874 to the last in 1886. Impressionism was characterized by homogeneity and true broken color style.

\section{BROKEN COLOR OF THE IMPRESSIONISTS}

What is the broken color style of the Impressionists? This question may be answered generally, but specifically it is difficult. While much has been written about Impressionism, the Impressionist's style remains elusive. The respective styles of Impressionism vary widely between artists, between early and later styles, and within a single painting. We therefore are faced with the paradoxical problem of differentiating between the general characteristics of broken color of individual Impressionists. If an explanation of specific 
styles of individual Impressionists were attempted, the topic would be infinite; therefore, a general approach must be followed.

\section{The Major Aim of Impressionism}

The major aim was to record the appearance of their subject as conditioned by the light falling on it without any preconditions of any kind. They felt a painting must be executed at the site and nothing added to them in the studio. They became fascinated by the light which changed with weather and the time of day; the light which the Impressionists painted was various, and so were the means employed to suggest them.

\section{Method}

After 1871, the broken color style was expanded. The small brush strokes already used for reflections in water were now applied to trees, houses, sky, hills, and all the elements of the landscape. The brush stroke used in breaking color appears as spots, hatchings, comma strokes and a multitude of other indefinable forms. The strokes may be broad, thin, blended, blurred, or dragged with heavy pigment and tinted varnish. These methods were used dependent on the effect these artists wanted.

John Rewald described a time when Renoir and Monet met to paint on the banks of the Seine after they both adopted the comma-like brush stroke.

The surface of their canvases were thus covered with a vibrating tissue of small dots and strokes, none of which by itself defined any form, yet all of which contributed to create not only a particular feature of the chosen motif but even more the sunny air which bathed it and marked trees, grass, houses and 
water with specific character of the day, if not the hour. Nature was no longer, as for the Barbizon painters, an object source of pure sensations and these sensations could best be reproduced by a technique of small dots and strokes which - instead of insisting on details - retained the general impression in all its richness of color and life.28

\section{Affect of Science}

Pigment. The introduction of tube-encased colors after 1841 and the new variety of chemical pigments combined to offer the painter a handy source of almost any color, clean and ready for his purpose. The artists, observing nature in terms of light rather than form, could match the shadows and lights with tints applied directly to the canvas creating rich surface of pure hues. The tube paints released the artists from the studio to undertake outdoor painting with a far richer palette.

Camera. Photography opened new vistas to artists; it showed painters natural details which sometimes escaped them and frequently revealed familiar scenes at a novel angle. Up to about 1871 the snapshot was a rarity and not developed until 1875.

Bazille and Claude Monet made use of the camera for some of their pictures; Monet's painting, Women in a Carden was composed from photographs that Bazille showed him.29

Studies on Color. The books written by Michel Eugene Chevreul and Ogden Robd were influences on Impressionism and Neo-Impressionism. We are more aware of the effect of science upon the

$28 \mathrm{John}$ Rewald, History of Impressionism, rev, and enl, ed., (New York: Museum of Modern Art, 1961), p. 234.

29Maurice Serullaz, Impressionist Painters, (New York: Universal Book Inc., 1960), p. 50 . 
Neo-Impressionists than Impressionism because most Impressionists were reticent in writing on color.

The Impressionist Palette

The Impressionist's palette 30 was composed of white, rose madder, vermilion red, cadmium yellow light, orange, cerulean and ultramarine blue, yellow ocher, burnt sienna, colbalt violet and black (Figure 3). The selection of hues is not complicated because these artist did little mixing and painted rapidly. The broken color effects in Impressionism depended on a palette of pure colors where pastel tints may be

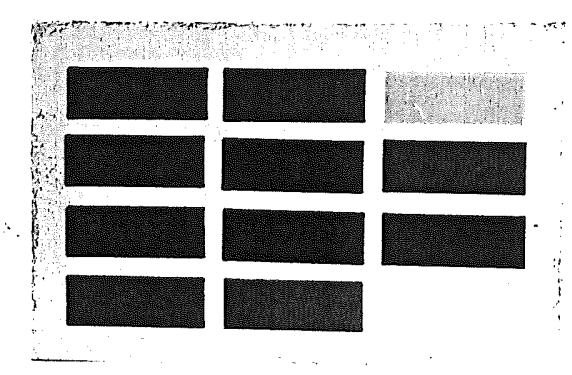

Figure 3. Impressionist Palette.

mixed quickly and then placed upon a white ground as though they were light sources.

The use of clear pigment in a rainbow variety opened the way for the achievements of hitherto undreamed of effects. Lighter, purer blues gave skies a new brilliance, strong reds and oranges evoked the sunset, and combinations of many colors gave surface of water in pond or river a far more active part in the drama of light. .31

Therefore, prismatic hues were essential to the broken color style.

30 Birren, History of Color in Painting, p. 107.

31 Joseph Stone, "The Art of Impressionism," Arts Yearbook,

(New York: Arts Digest Inc., 1958), p. 128. 
26

Summary

Generally, from 1870 may be called the "golden decade"

of Impressionism. Each of its founders, having reached maturity, went forth on his own way. Impressionism ends the struggle for natural illusion which began with Masaccio in the Renaissance. The introauction of color into the stream of art so forcefully helps set the battle of modern art. In different ways the impressionist painter attempted to discover new techniques in which pigment could be made to appear more intense and vibrant in their efforts to capture the scintillating quality of light. Oil pigment could not compete with the sunlight. Broken color techniques of juxtaposition of strokes solved this problem and, therefore, presented the world with an era of its most vibrant paintings. 
The new generation of artists sprang from the roots of Impressionism with the idea to put structure into the fluid style of Impressionism. The Neo-Impressionists developed a calculated system based on scientific study and applied their methods within painting. The style is most represented within Seurat's painting (Figure 4), A Sunday Afternoon on the Island of La Grande Jatte. The Impressionists

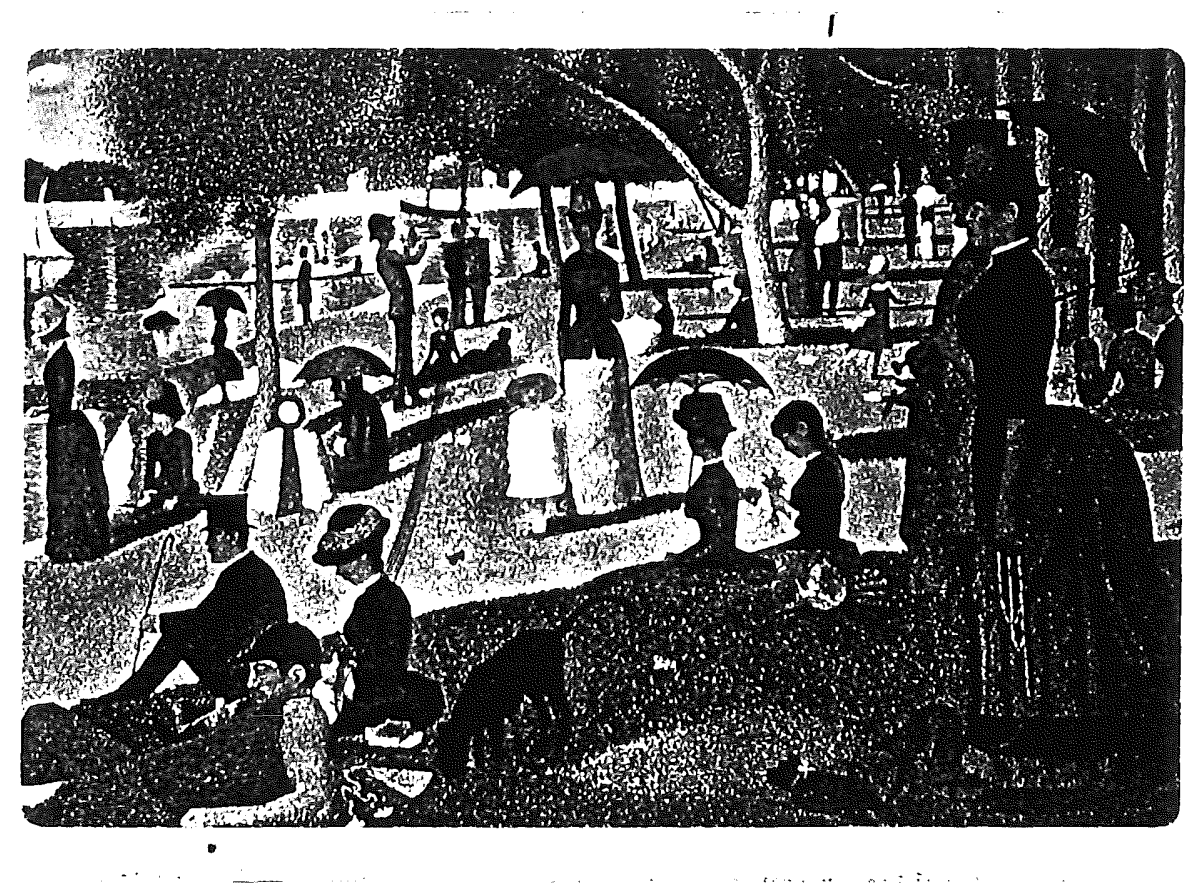

Figure 4. Seurat: A Sunday Afternoon on the Island of La Grande Jatte, $1884-86,841 / 4 \times 1201 / 4$ in.

were artists who tried to work freely and on impulse. To them art was a matter of release rather than control. With Neo-Impressionism light 
was studied as small areas of pigment placed contiguously in a scientifically calculated manner in which the eye perceives pigment as light in a new controlled approach to the visual awareness of color. Neo-Impressionism, therefore, is a new approach. Faber Birren stated in his book, History of Color in Painting:

One sees the beginning of a psychological attitude towards the spectrum which intrigue Seurat, Signac, Kandinsky, and literally dozens of Abstract Expressionists of the midtwentieth century.

\section{NEO-IMPRESSIONISTS}

Georges Seurat emerged as a progressive painter and leader of the Neo-Impressionist group. Other followers of Neo-Impressionism were a group of artists namely, Paul Signac, Henri-Emond Cross, Charles Angrand and Albert Dubois-Pillet who formed the new Societé de Independents. Later Signac, Pissarro, and his son Lucien took up the new discipline. Rewald quotes a letter written by Pissarro to DurandRuel in which he states:

It is M. Seurat, an artist of great merit, who was first to conceive of the idea and apply the scientific theory after having made thorough studies. I have merely followed his lead...

\section{BROKEN COLOR OF THE NEO-IMPRESSIONISTS}

Divisionalism is a new term which evolved out of the Neo-Impressionism style. Divisionalism is the breaking-up of color into its component parts; this may be done in several methods of pigment application. Pointilism is another term often used in place of divisionalism. Pointilism more closely defined as the application of dots of 
uniform size.

\section{Evolution of Divisionalism}

The evolution of divisionalism will begin with its founder, Georges Seurat. From the year 1876, when Seurat began to paint, to 1884, he experimented with a wide variety of styles of painting. During this formative period he turned for advice to a group of scientific and theoretical writing on the nature of color. "He turned to every source, whether textual of pictorial, that might contribute to his discovery of a formula for optical painting." 32

Written Sources. Neo-Impressionism was marked by an absorbing interest in science that pervaded the new art. The science was eagerly accepted by the painters. Art journals published essays on the science of color. Artists were advised to devote themselves to such inquiries. Two authors who contributed strongly were Michel Eugéne Chevreul and the American, Ogden Rood. The main body of Chevreul's book, The Prineiples of Harmony and Contrast of Colors, explored the relationship of juxtaposed hues, harmony, afterimages? 33 and optical effects of fusion of hues in the retina of the eye. Ogden Rood's text, Modern Chromatics, explored in painter's language areas

32Homer, Seurat and the Science of Painting, p. 19.

33 The knowledge of the visual pheonomenon of afterimage will be an aid to the painter. The Higgins Ink Company explains in their book, Color Digest, that in viewing blue, for example, the blue consumes a chemical of chemicals and leaves others in the eye to register the blue. While this process is going on nature makes an effort to adjust itself and rushes an additional supply of chemicals consumed which register as yellow or the complement of blue. When the stimulus of blue is removed, the excess of the chemical stimulus for yellow remains with you, therefore, "see yellow" until the eye adjusts itself and regains normalcy. 
colors, complementary colors, contrast and color combinations. The scientists Blanc, Dove, Henry, Helmholz, and Sutter contributed important color research during this period.

Pictorial Sources. Seurat learned from Delacroix his method of juxtapostion of complementary hues to create rich surfaces. Delacroix ascertained that a color is only beautiful if it vibrates with a flickering luster which gives it life. The painting by the Impressionists were relevant to the Neo-Impressionists through color, light, and a taste for nature.

\section{Divisionalism}

The rational method taken by Seurat in his first major painting, Une Baignade was to gather material. He did this in two ways: first, he went out and made quick color studies on the banks of the Seine; second,

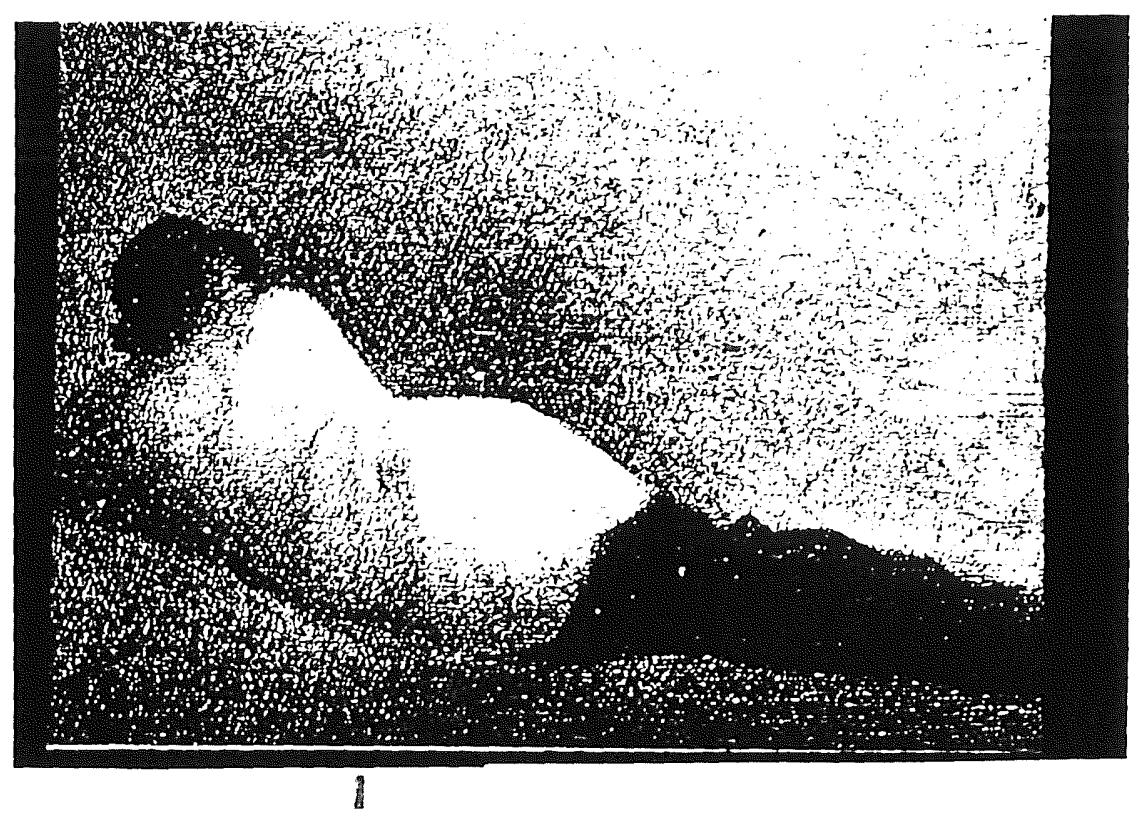

Figure 5. Study for "Une Baignade" (conté crayon drawing) 1883-84. 
he made studies of models in the studio which were done in conte crayon utilizing the principle of optical mixture. Study for Une Baignade (Figure 5) was done on rough Ingres paper. The crayon could not penetrate the deepest hollows of the surface of the paper which created a surface quality of white spots. When viewed at a distance the specks of white mix optically with the conte crayon and an effect of atmospheric transparency and luminosity is the result. This same effect will result when pigment is "dry-brushed" over underlying color.

The broken brush strokes within the finished painting were varied and the palette hues were both prismatic and earth colors; therefore, from the pure science view, the painting was still imperfect. The earth colors dulled the optical mixtures and the passages of brush technique were varied which created only certain areas of optical mixture.

\section{La Grande Jatte}

La Crande Jatte (Figure 4) was a "landmark" of now fully established Neo-Impressionism. This is the second of his major paintings. Elimination of earth colors, use of a uniform brushstroke, the controlling of color found in nature, and the treatment of the total canvas by scientific laws of optics were the unifying elements of the composition.

Studies. The data was accumulated from small oil studies inspired in an impressionist quality of shimmering vibrating colors. The studies were painted quickly with strokes in a criss-cross manner. Shadows were enforced with blue pigment and the sunlit effect was achieved by strokes of orange. The final study is remarkably effective such as mixing 
in conveying a sense of pulsating sunlight and luminous shadow. These studies were close to natural colors in nature and not finished work according to scientific law. As with Seurat's earlier painting, studies were made in conté crayon to establish form and position for models and to establish value contrasts for the final painting.

Final Painting. The final painting of La Grande Jatte was finished after two years of work which stands as the technique, method, and theory of Neo-Impressionism. The total surface was painted in a unified manner. Local colors were superimposed with other hues to control the optical effect. The painting was shown in the final Impressionist exhibition in 1886.

\section{Viewing Broken Color}

The degree of optical mixture of various colored hues depends on the size of the colored dots and the viewer's distance from the canvas. Standing very close one can see all individual spots of pigment; but if one moves back gradually, the spots would eventually fuse due to the imperfection of the eye. However, a point before fusion occurs, the hues would become lustrous creating a luminous surface. The hues mixed in this manner are richer than the subtractive mixture on the palette. If a lustrous gray is wanted, as Delacroix discovered, place complements contiguous to one another.

\section{Surmary}

Color can therefore be broken by separation and juxtaposed in many ways to create a lustrous surface quality within painting. Impressionism, with its loose free style will influence contemporary 
painters far more than the structured manner of Neo-Impressionism. Pigment does not have the strength of light; therefore, only partial additive mixtures will occur in pigment.

The broken color style was continued after the death of Seurat in 1891 by Signac and Cross. Matisse worked with Signac and Cross in 1904 and may have contributed to the Fauves in 1905. The Italian Futurists carried on with the theories of divided colors after the turn of the century. The total impact of the broken color style upon the art movement would be infinite due to the quality of artists being affected such as Van Gogh or Cézanne. 
CHAPTER VI

\section{STUDIES OF DIVISIONALISM}

An emphasis will be taken within this chapter to explore the aspects of broken color of the Neo-Impressionist style through actual painting related to Seurat's pointilism technique.

\section{DESCRIPTION OF PROBLEM}

The painting problem was undertaken to gain insight into the aspects of color within divisionalism. An orderly format was planned. First in order was to do research by reading important texts which were relevant to the topic of research. The compositions of four major paintings were then planned and within each painting the subject and light problems were varied in order to develop more understanding of the divisionalist technique. Studies were then made to establish major compositional structure. The final paintings were begun and finished weeks later after placing spots of multi-colored hues upon the canvas, dot after dot.

\section{TECHNICAI ASPECTS}

The size of all paintings were $28 \times 38$ inches in dimension primarily for the ease of construction and handling. The paint mediums used were oil and acrylic and at times combined. Acrylic paint was superior due to the rapid drying factor. A small size number three 
flat red sable brush was used to create dots of uniform size in about thirty square feet contained within the surface of the four paintings; this is comparable to the surface area of Seurat's La Grande Jatte which is sixty-two square feet.

\section{FOUR STUDIES OF POINTILISM}

The subject of each painting was selected as an area to explore within the scope of pointilism. The subject of each was placed under various lighting conditions such as the natural light of the sun or artificial illumination of a candle or electric bulb. The subject titles of the four major paintings are Still Life with Bucket, Evening Harbor, Topless Dancer, and Dock Study. A descriptive analysis of each painting will more fully explain the method of exploration.

\section{Still Life with Bucket}

The method undertaken within this painting was similar to Seurat's in that studies were done through drawings in value ranges and in freely applied color before the final painting.

Ink Pointilism Study. (Figure 6) Seurat used conté crayon to work out in advance the problem of chiaroscuro within his paintings. Instead of using conté crayon, small black dots from a felt-tipped pen were applied to heavy illustration board glued to masonite. When the ink study was completed it was sprayed with clear plastic spray to protect it from atmospheric conditions.

Seurat worked out the compositional elements in advance, not only the value problem, but the forms and form relationships. Within the 
ink study, values could be deepened by the addition of more dots to develop the design pattern within the final painting.

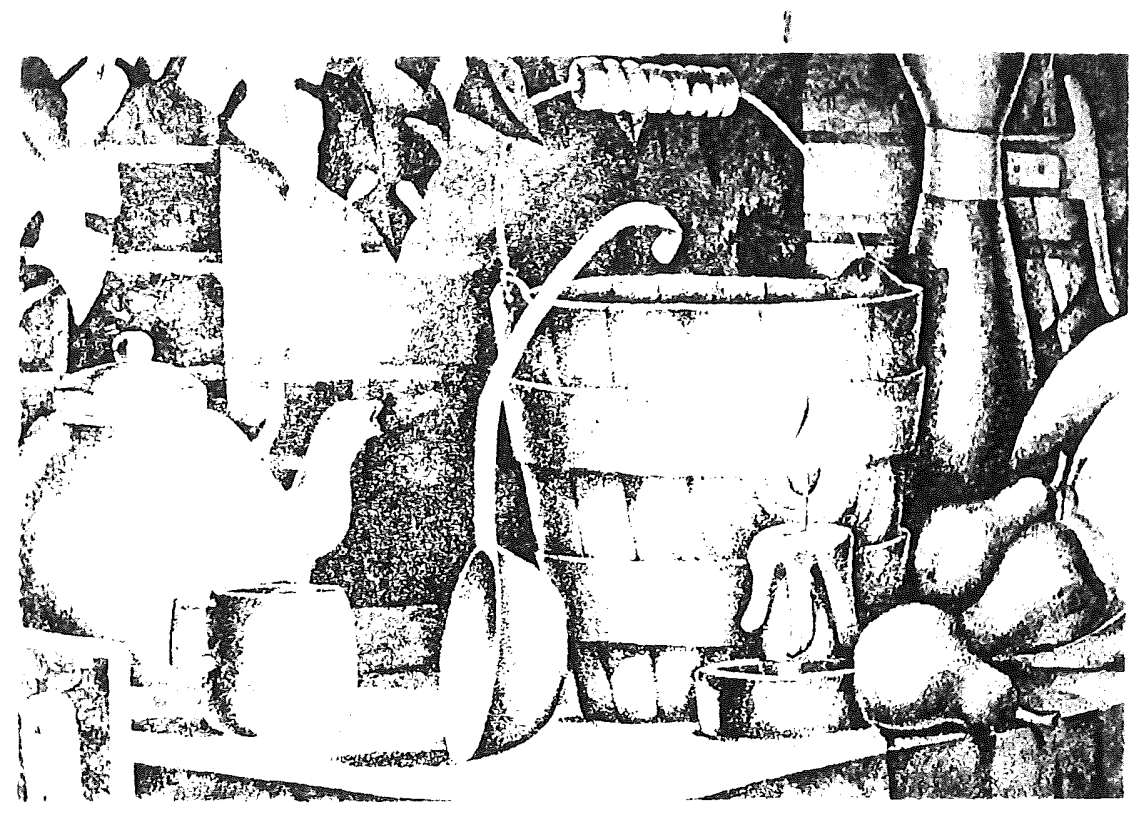

Figure 6. Ink Pointilism Study, $28 \times 38$ in., Felt Pen.

The surface of the ink pointilism study develops a luminous quality when viewed at the proper distance. According to Seurat's theory a point between figure six and figure seven the surface should develop an amount of luster. This is due to the eye's inability to focus clearly on the dots at a distance; at a point, however, the eye begins to register the isolated spots. This, then, is the proper viewing distance in which the surface becomes lustrous.

Color Study, (Figure 8) The color study was taken directly from the still life to help establish the color pattern of the final painting. Color alone is the prime concern; the drawings of specific objects were loosely established. Only a selection of a palette of 
prismatic hues were used, black and earth colors were omitted. Little mixing other than the tinting action of white was done and these pure hues were placed upon the canvas as patches of contiguous colors corresponding to the local color (Figure 9). The use of acrylic pigment was an aid in keeping pigment pure due to the speed of drying. This factor became very helpful in quick color studies.

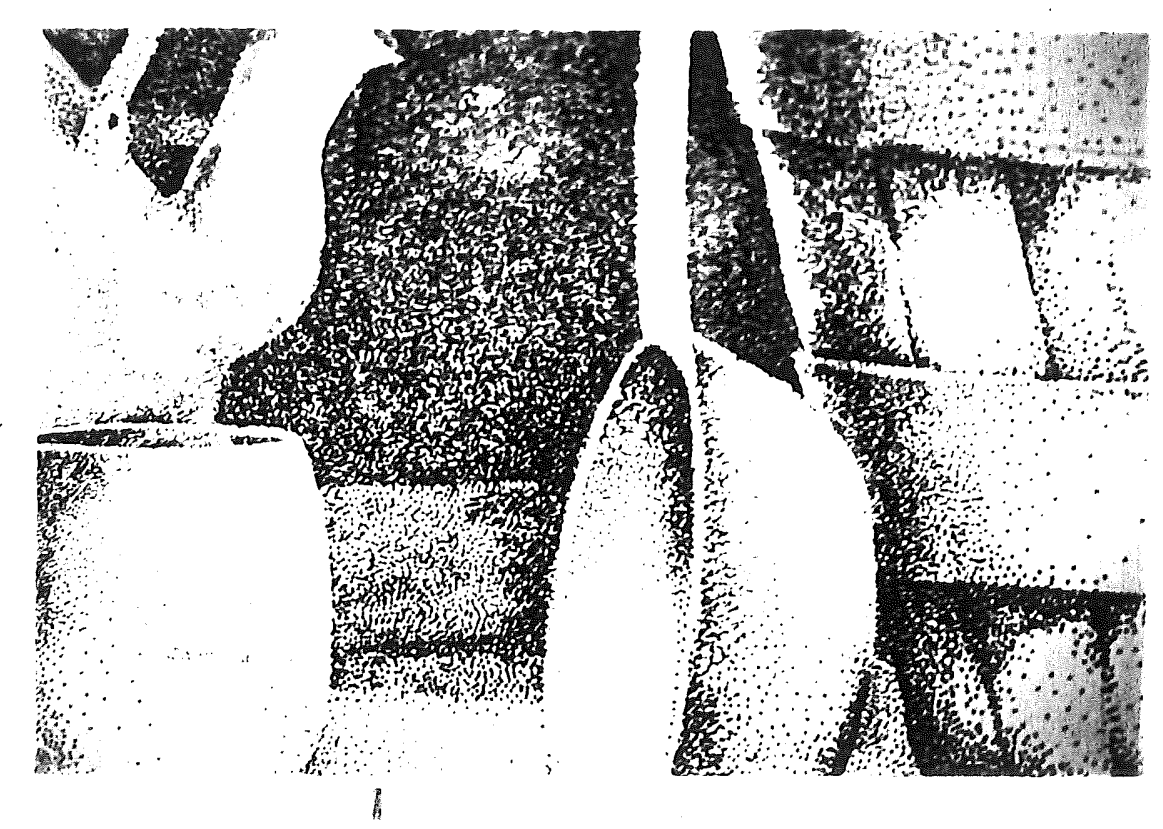

Figure 7. The close-up of the felt pen ink study.

Final Painting. (Figure 10) The compositional structure of the final painting, Still life with Bucket, was planned carefully. The ink study (Figure 6) developed the light dark pattern as well as an experiment in ink pointilism; the color study (Figure 8) developed the color pattern in a loose fluid style. Following these studies the final painting was undertaken.

The aspect of light, whether indoors or outdoors, must be carefully 


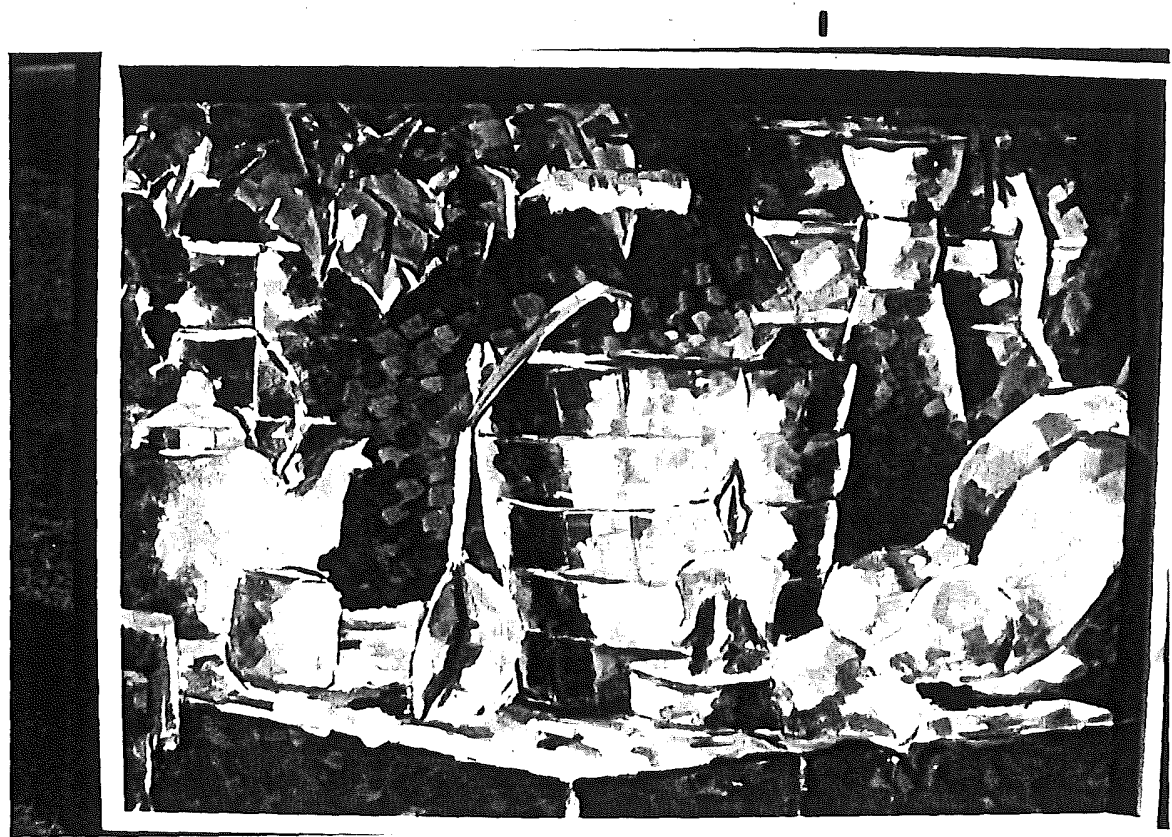

Figure 8. Color study of the final painting, $28 \times 38$ in.

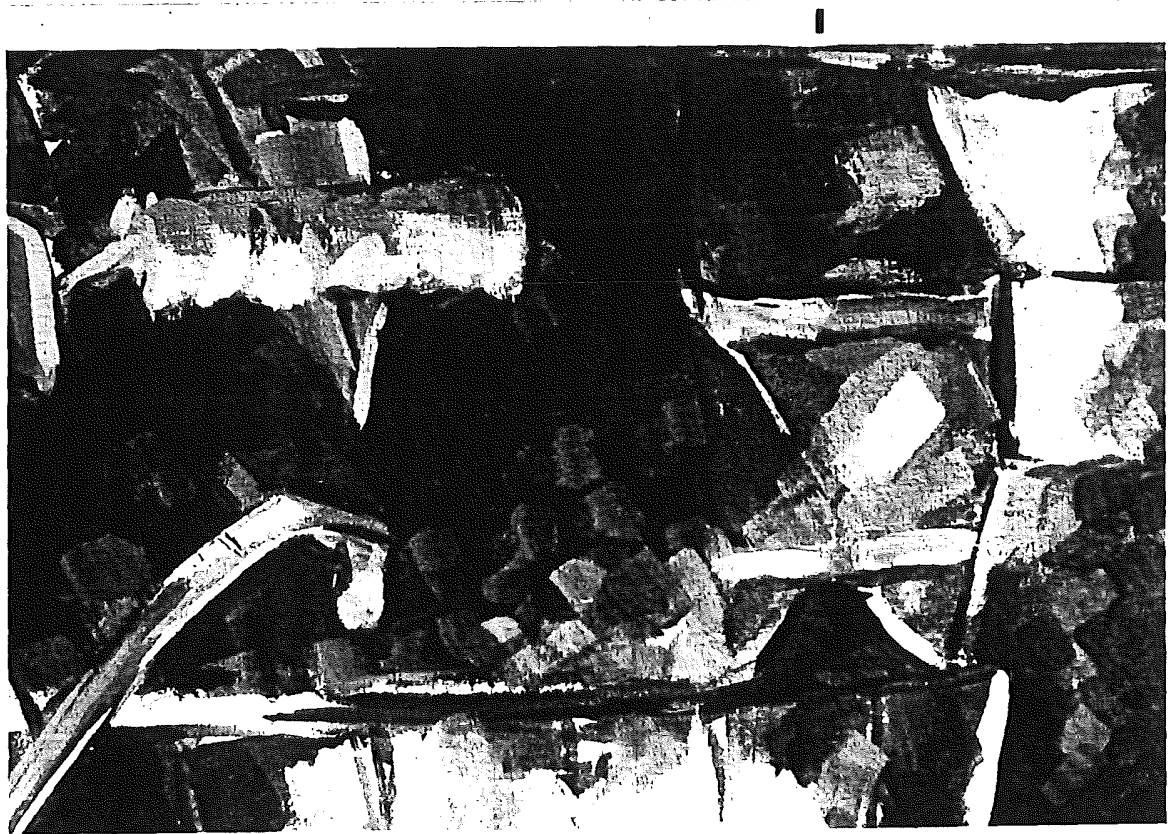

Figure 9. Close-up showing the looseness of brush strokes. 
considered. The artificial light of the candle was utilized to help develop the chiaroscuro and to unify the composition by flecks of yellow-orange throughout. Acrylic fluorescent hues were used sparingly to heighten certain parts such as light yellow near the candle and redorange dots in the major blue areas. Two dominant areas contain complementary hues. The red table cloth and bricks are complementary to the

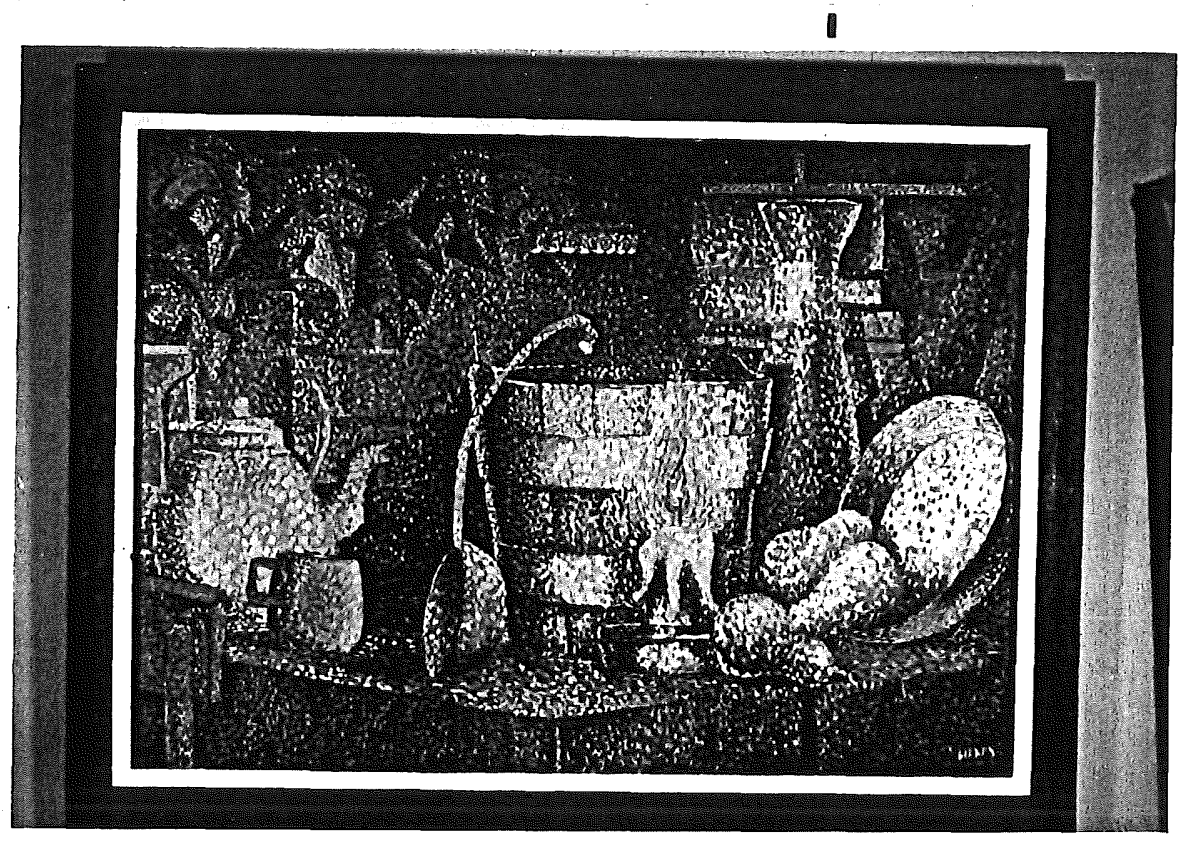

Figure 10. Still Life with Bucket, Oil and Acrylic.

blue-green background and curtain. These major passages of color each according ta the law of simultaneous contrast intensify each other. The red becomes more intense by taking the complement of the blue-green and the blue-green is aided by the complement of the red. On closer inspection the large areas were optically adjusted through the addition of small spots of complementary hues (Figure 11). The shadow areas were neutralized also by the complements added; the yellow tea kettle has 
spots of violet in the shadowed surface. Delacroix noticed the yellow cabs of Paris cast violet shadows. Browns and blacks were absent from the shadows as Manet suggested in many of his paintings. By the juxtaposition of hues, shadows develop a rich luster.

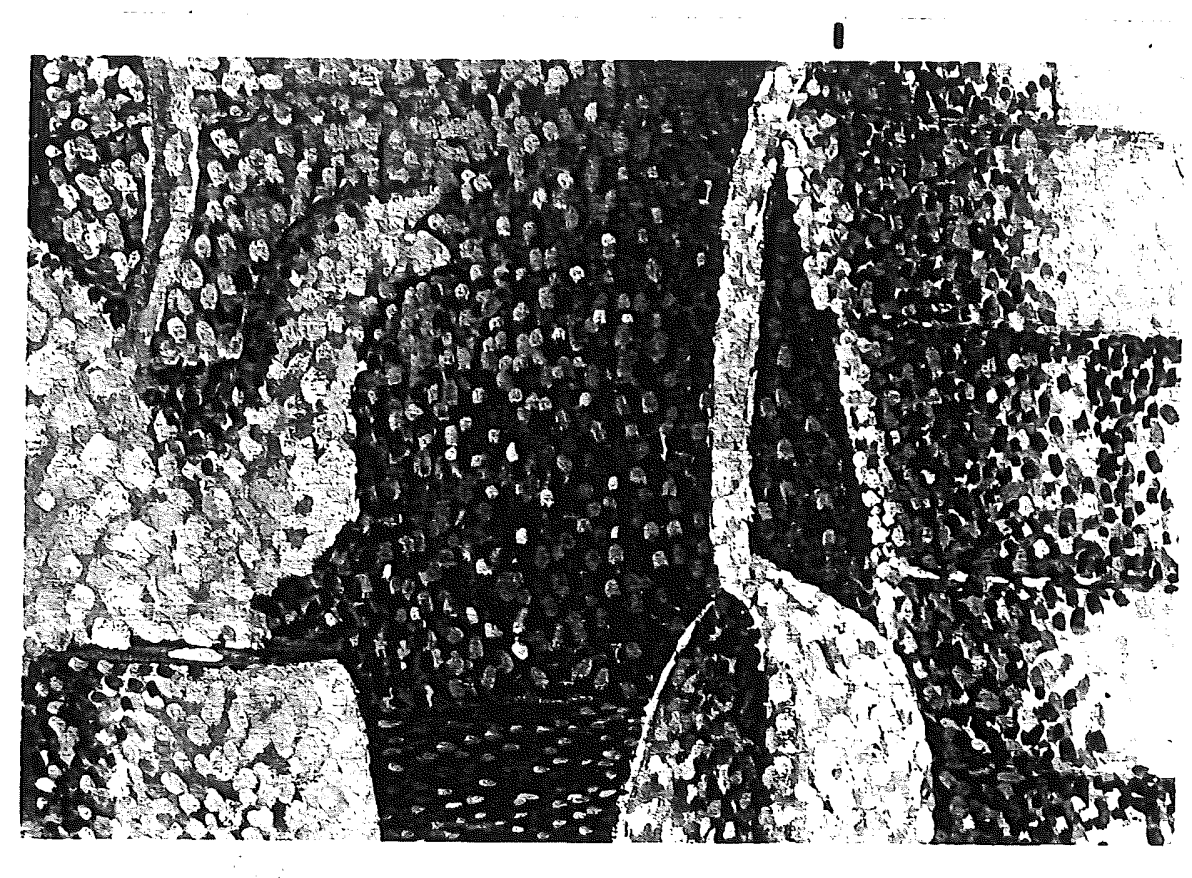

Figure 11. The close-up of the final painting.

The final painting has therefore been developed through an orderly sequence and with proper lighting and the correct viewing distance the painting has a flickering vibrant surface which is an example of the broken color of the Neo-Impressionists.

\section{Evening Harbor}

The theme of the study (Figure 12) was inspired by Monet's painting, Houses of Parliament. Monet captured the yellow-orange sun shining through the fog and appearing again reflected upon the water. The shadows were Iuminous due to the hues of blue and blue-violet which 
were a fusion of many strokes. However, in Evening Harbor the strokes were not fused but applied as a pure spot of colored pigment. A shimmering effect was obtained through juxtaposition of complements and the values of a single hue. The intensity was controlled, not by mixing pigment subtractively on the palette, but by optical fusion of juxtaposed complements. Natural illumination from the setting sun is diffused through the structure of buildings and the fog-like clouds which hover low in the sky. The major light, being warm, is juxtaposed with the cool areas placing receding passages of blue and the advancing properties of the red.

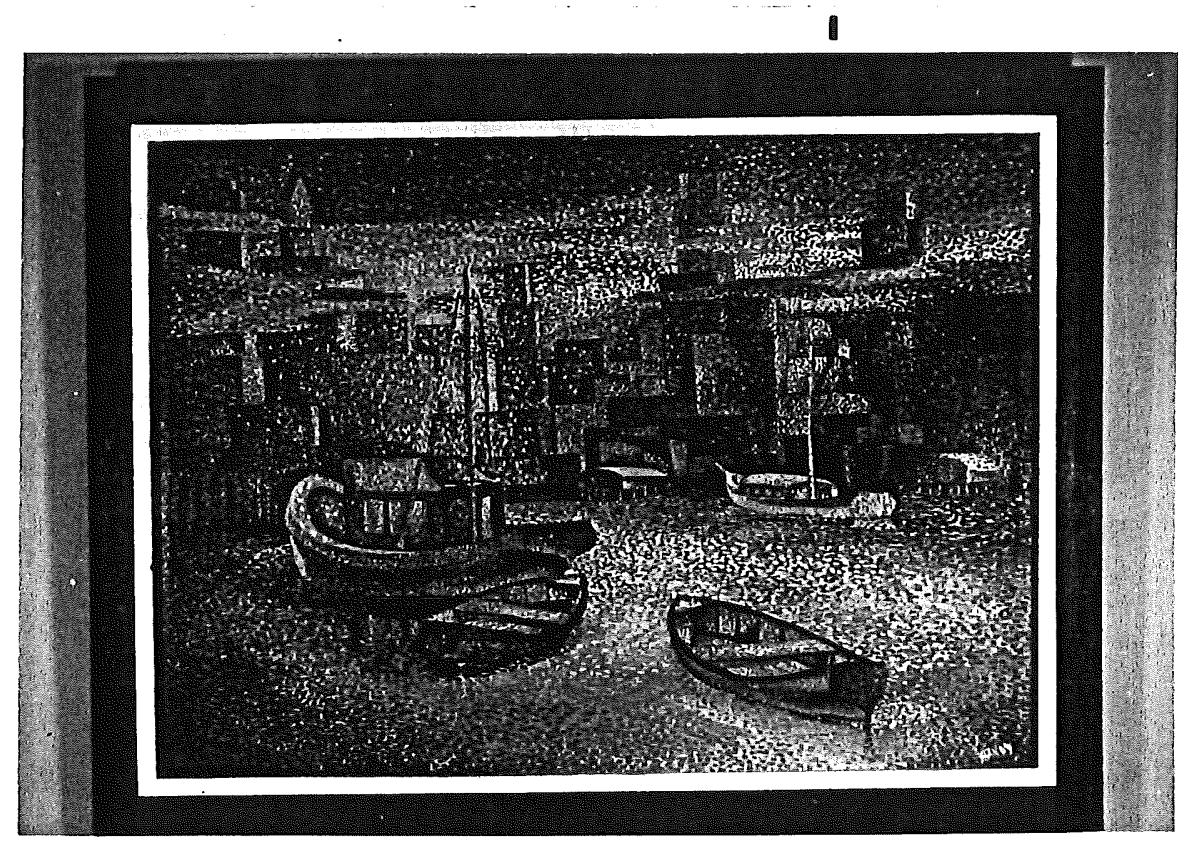

Figure 12. Evening Harbor, 28 x 38 in., Acrylic and Oil.

\section{Topless Dancer}

The subject of the third painting (Figure 13) was a figure placed into the illumination of light, as were the other pointilist 
studies. The illumination was to be directed upon the figure from the upper-right corner, flooding the figure with diffused light in a semi-dark room. The figure being the main motif was in full light; other figures were placed in shadow areas. The degree of illumination will effect all forms. Rood explains that:

...colors in strong illumination turn toward yellow and when still more strongly illuminated, bleach out. ...colors in shadow turn toward blue and in weaker light into violet black. 34

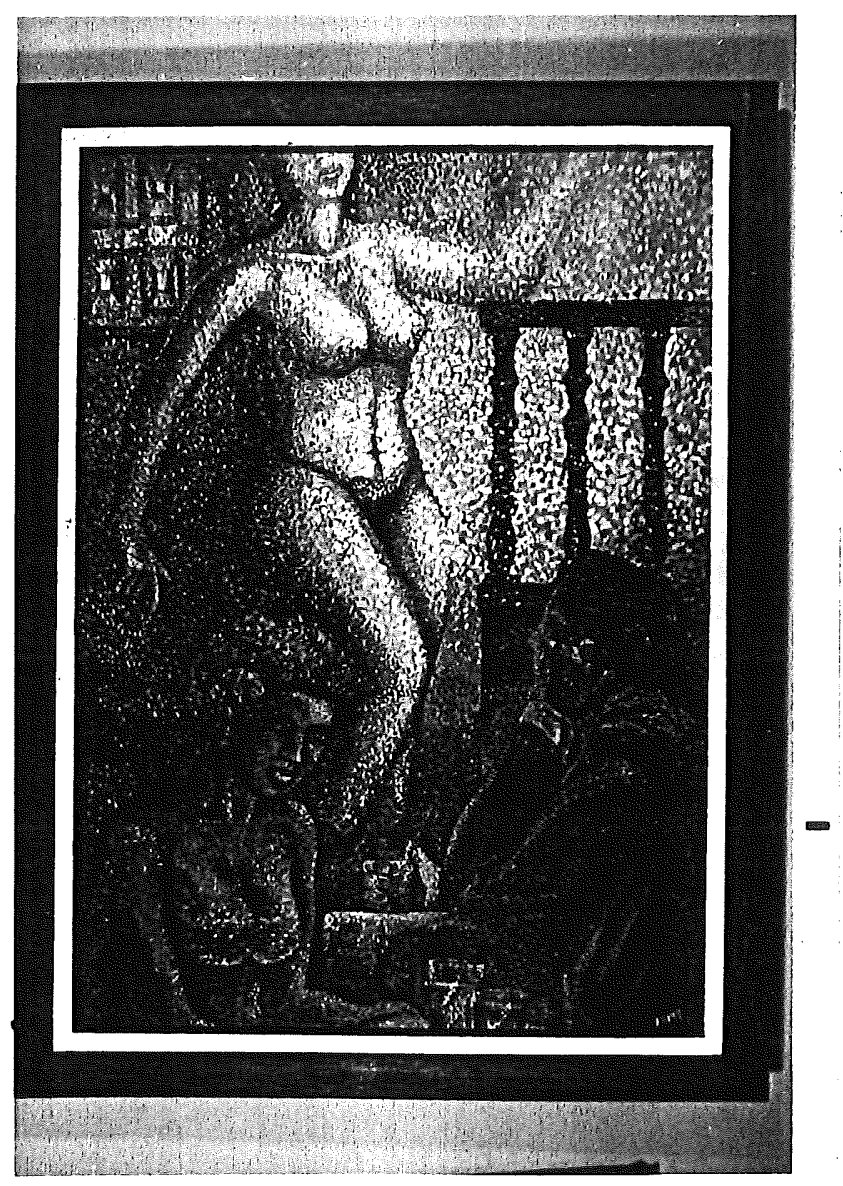

Figure 13. Topless Dancer, Acrylic.

34Rood, Color and Light in Painting, p. 189. 
Rood further explains there is a point at which colors tend neither towards yellow nor towards violet and exhibit themselves in their true colors which artists name local color.

\section{Dock Study}

The forth and final study in the pointilist technique was to explore effect of natural light upon a subject not within a nocturnal setting but in the light of the daylight. The light within this study was placed at the horizon; it was reflected upon the water and was reechoed throughout the composition. As with the other pointilist studies the shadows were turned toward blue and blue-violet. The values at the periphery were darkened to place emphasis upon the light source. The graphic description of details was an added problem to solve within this technique. This was done through value and hue contrasts.

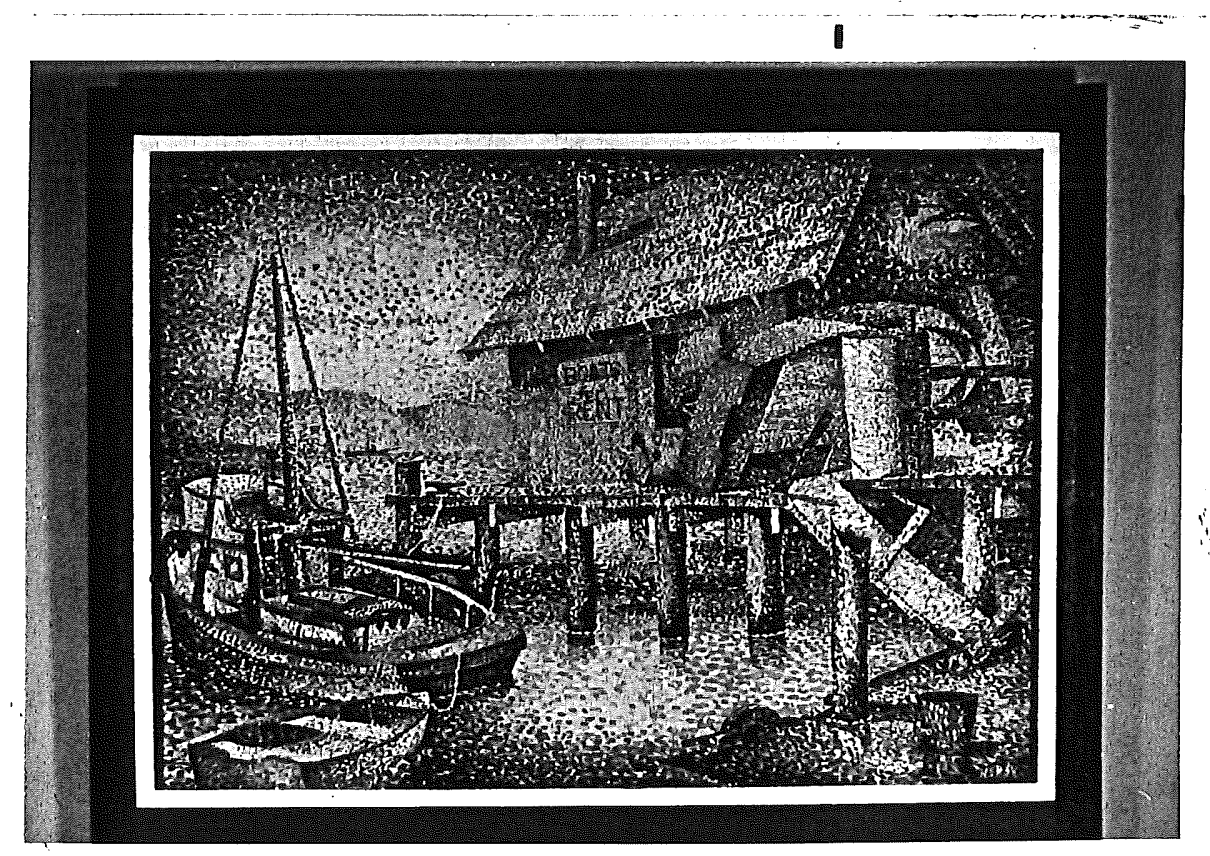

Figure 14. Dock Study, Acrylic. 
IV. SUMMARY

The involvement into painting in the pointilist technique has developed much insight into the many aspects of color. Color is far from passive; it can be altered and enriched through many combinations of values and hues. Pointilism has ended. There is, however, much yet to be gained from the inquiry into aspects of color and color perception. 


\section{A STUDY IN BRUSH STROKES}

Small comma-like strokes were found frequently in many of the Impressionists' paintings and especially in Renoir. The major aim of this study (Figure 15) was to explore the effects of breaking color, not in the science oriented pointilist technique, but a more fluid comma-like stroke.

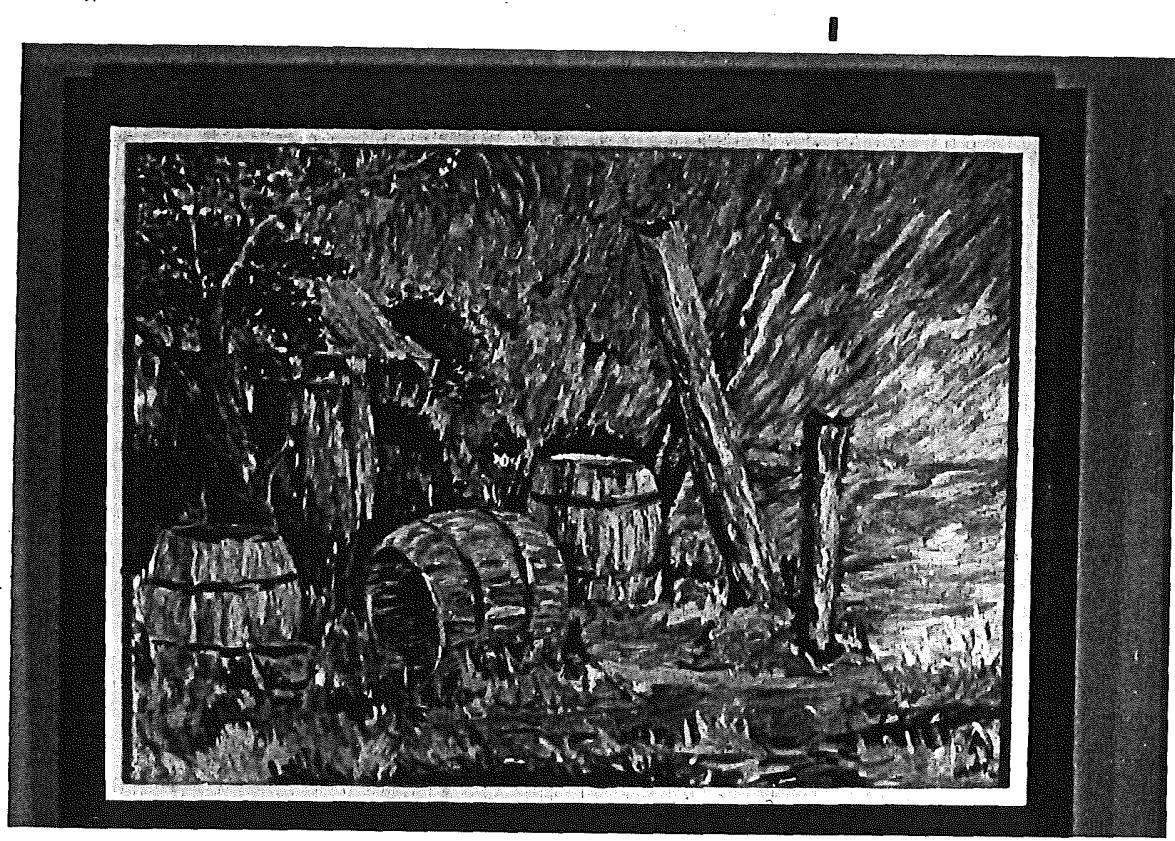

Figure 15. Three Barrels, Acrylic.

Hue and value were juxtaposed in long, thin strokes. Movement is created in the strokes of the sky, water, grass, trees, buildings, and barrels. 


\section{CHAPTER VIII}

\section{LANDSCAPE STUDIES}

Nature has always furnished the artist with countless examples of broken color. The Neo-Impressionist recorded it through the analysis of light as a multitude of dots; the Impressionist recorded it as patches of color. The paintings within this chapter record nature also, but as individual strokes of pigment applied to the canvas where no modeling and blending were done. These paintings are broken color landscape studies.

\section{TECHNICAL ASPECTS}

The paintings are primarily from the northwest; color studies and photographic slides and prints were utilized in planning the compositions. The final studies were finished in the studio. The primary media used was acrylic paint; however, oil and casein were used very sparingly. Modeling paste and jel were an aid in developing textural surfaces and transparency when needed. To facilitate the ease of handling, the size of each painting is $28 \times 38$ inches.

\section{PAINTINGS}

\section{Country Road}

The motif of this scene (Figure 16) was selected due to the dark and light masses that would lend itself to the study of broken color. 


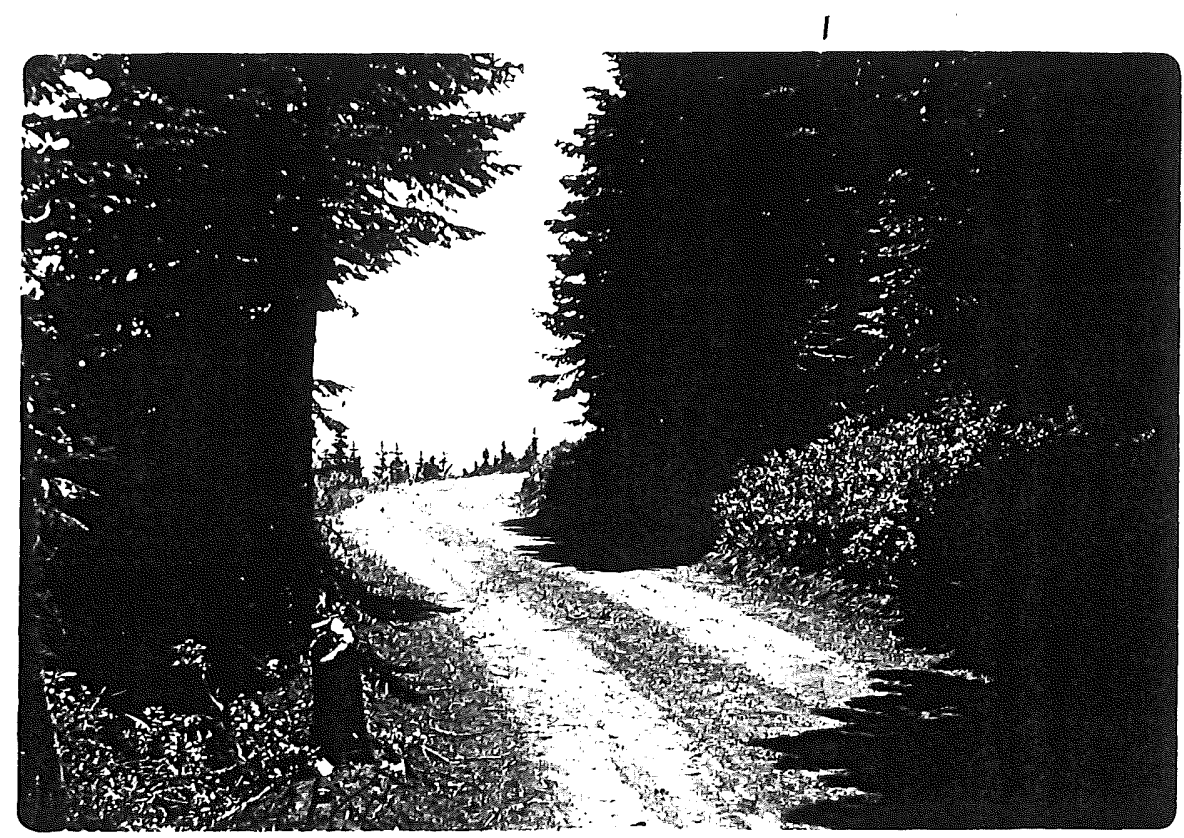

Figure 16. Print of Country Road.

If a comparison is made in the shadows of the print (Figure 16) and the final painting (Figure 17), a comparable quality is evident.

I

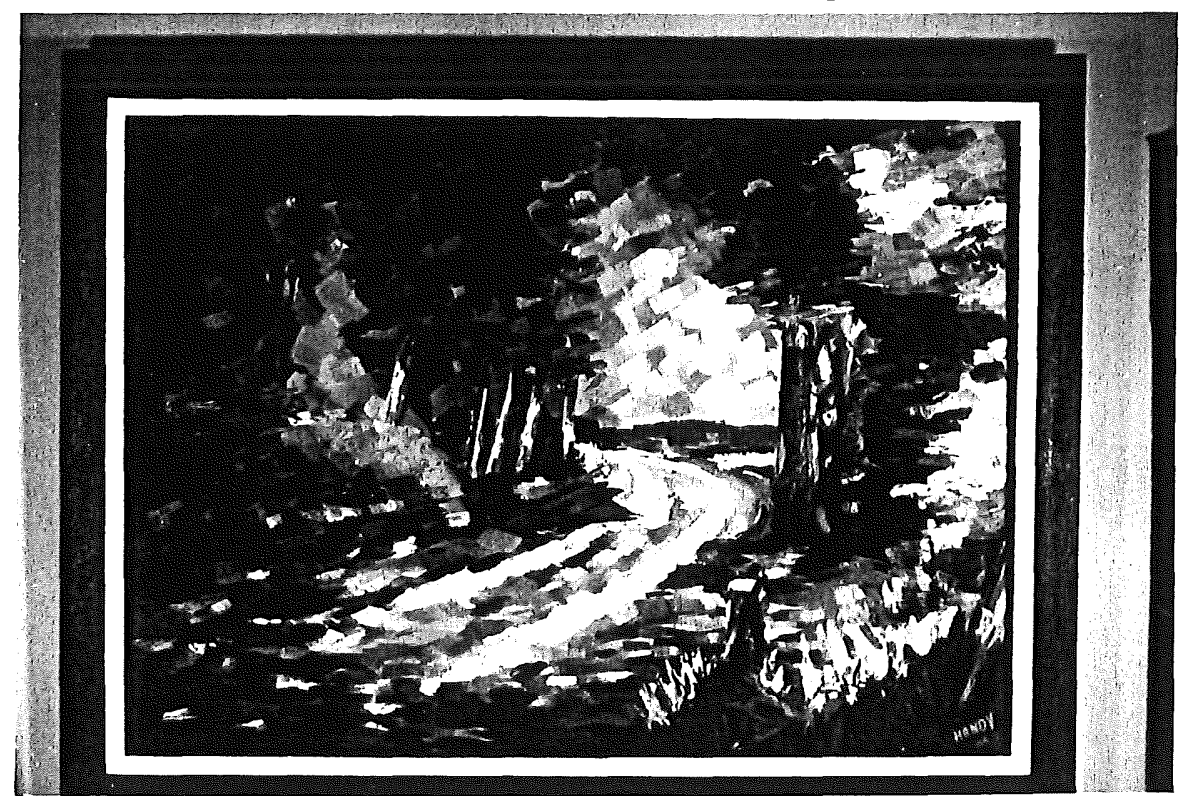

Figure 17. Country Road, Acrylic. 
Impressionist painters recorded light as patches of color. Below, by use of close-up photography, patches of pure hues are very evident in the print (Figure 18). The close-up was taken from the painting, Country Road (Figure 17). The sky has been painted as patches of light blue, white, green, and yellow. The hue of the sky has been repeated in the shadow area. The shadow becomes luminous due to the juxtaposition of dark violet and blue. A flickering luster has been created through the technique of dry-brush painting. The freedom of the loose brush handling adds to richness of broken color painting.

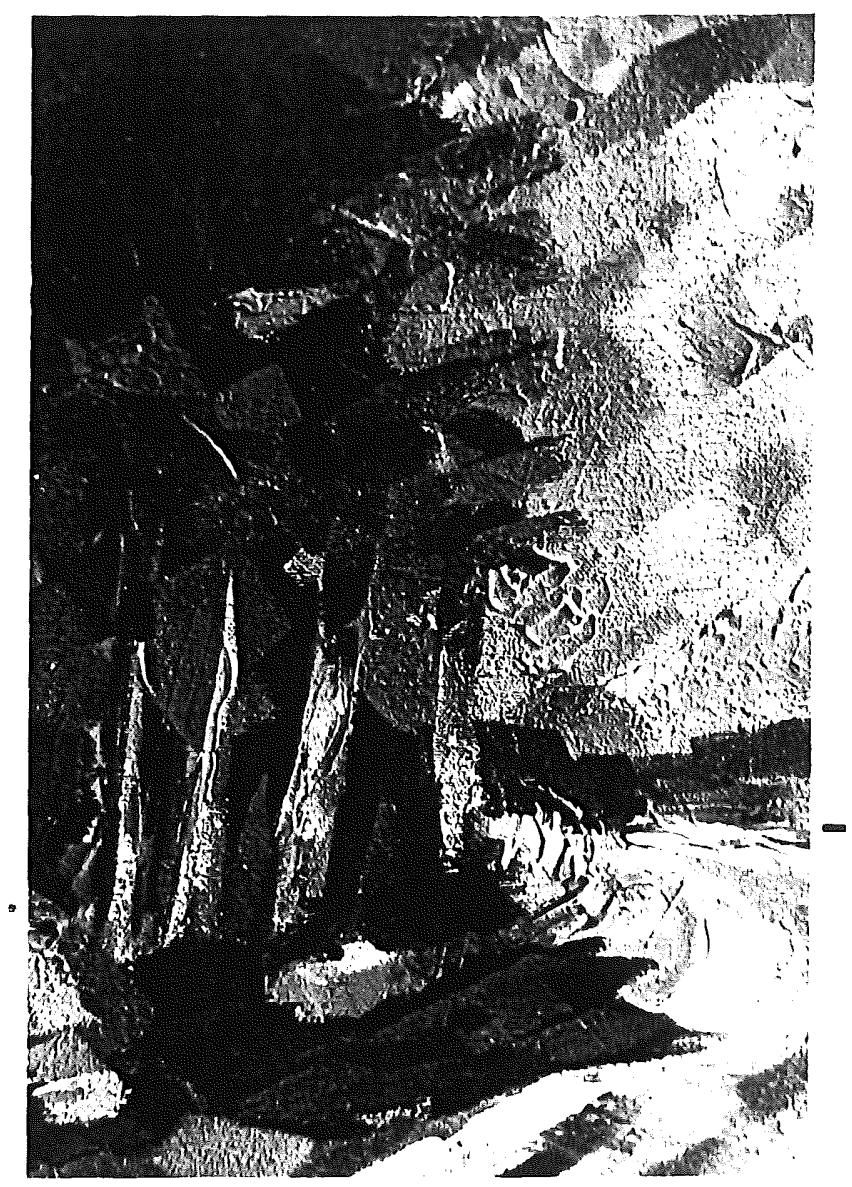

Figure 18. Close-up print of Country Road. 


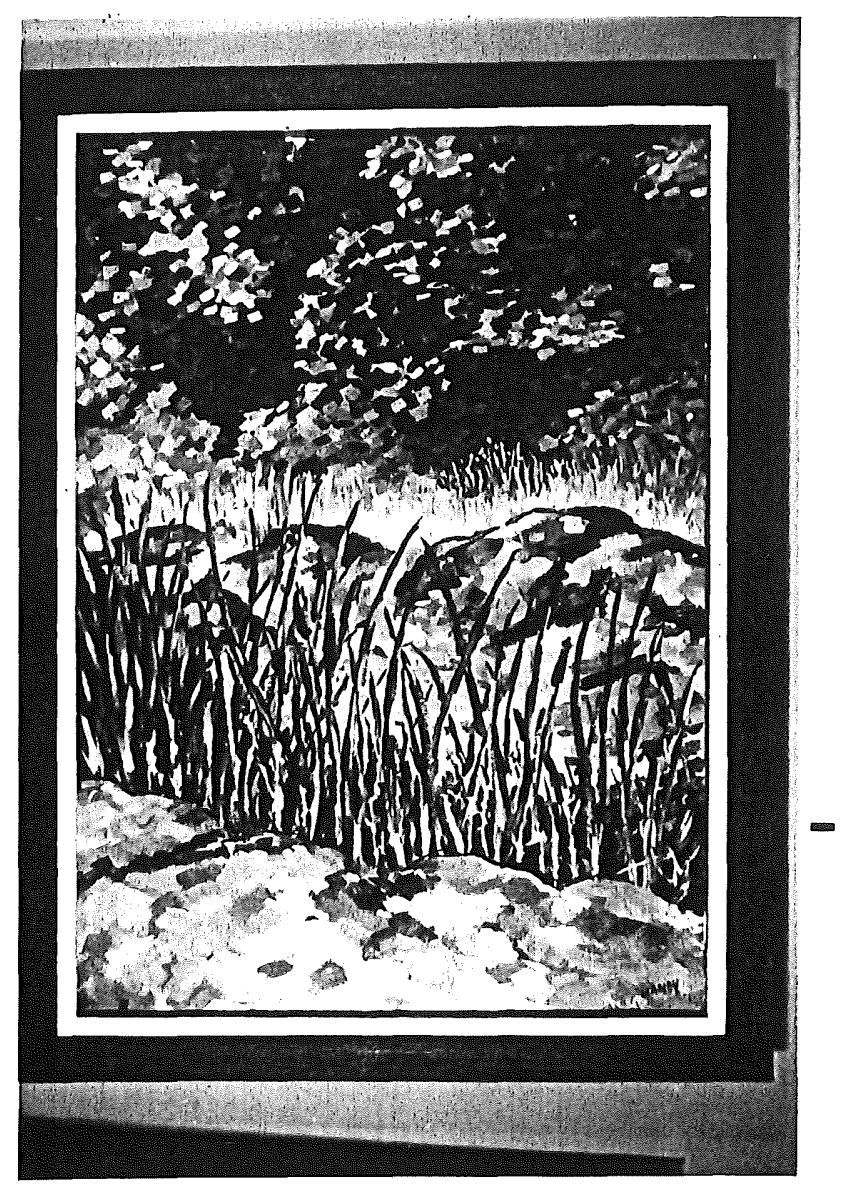

Figure 19. Cat Tails, Acrylic.

\section{Cat Tails}

The flickering pattern of broken hues causes the composition to become alive with richness. The foliage in the background has been broken into hues forming a rhythmic pattern of light and dark. The large rocks are but a network of broken hues. The cat tails themselves are created with vertically divided hues. Nature being alive with broken hues can be given added richness by the liberties taken by the artist to deepen values creating stronger contrast than within nature itself. A comparison may be made with the photograph (Figure 20) and the painting. 


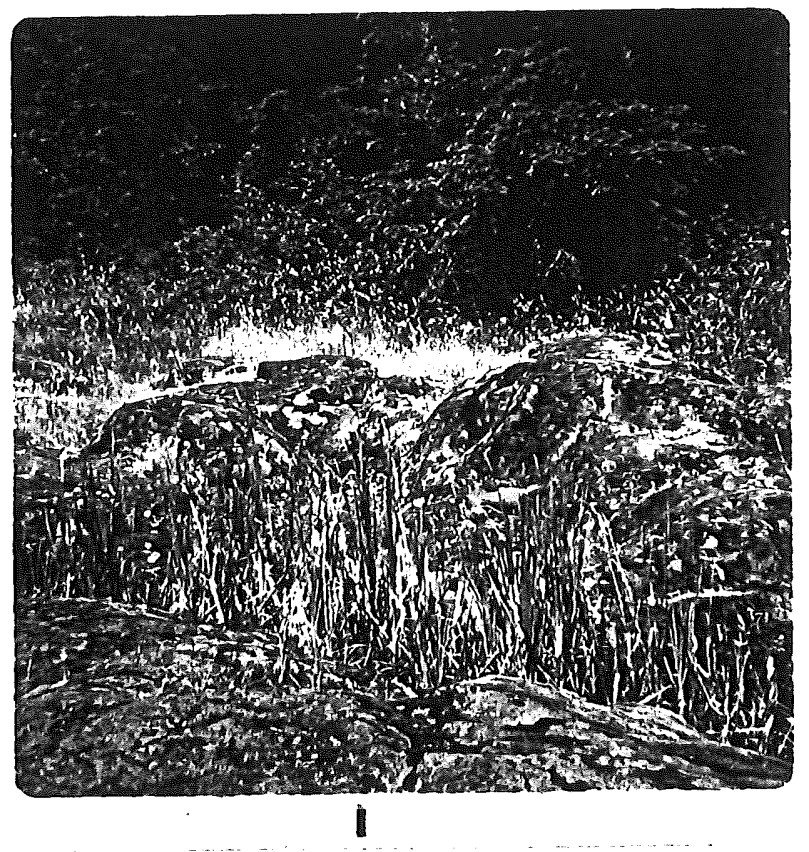

Figure 20. Print of Cat Tails.

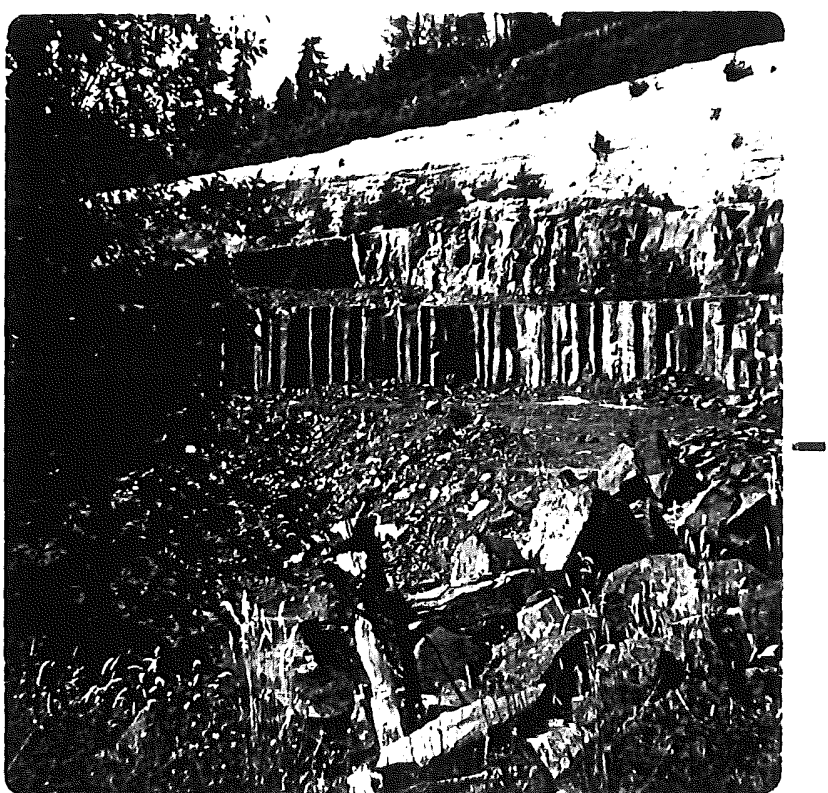

Figure 21. Print of Rock Quarry. 


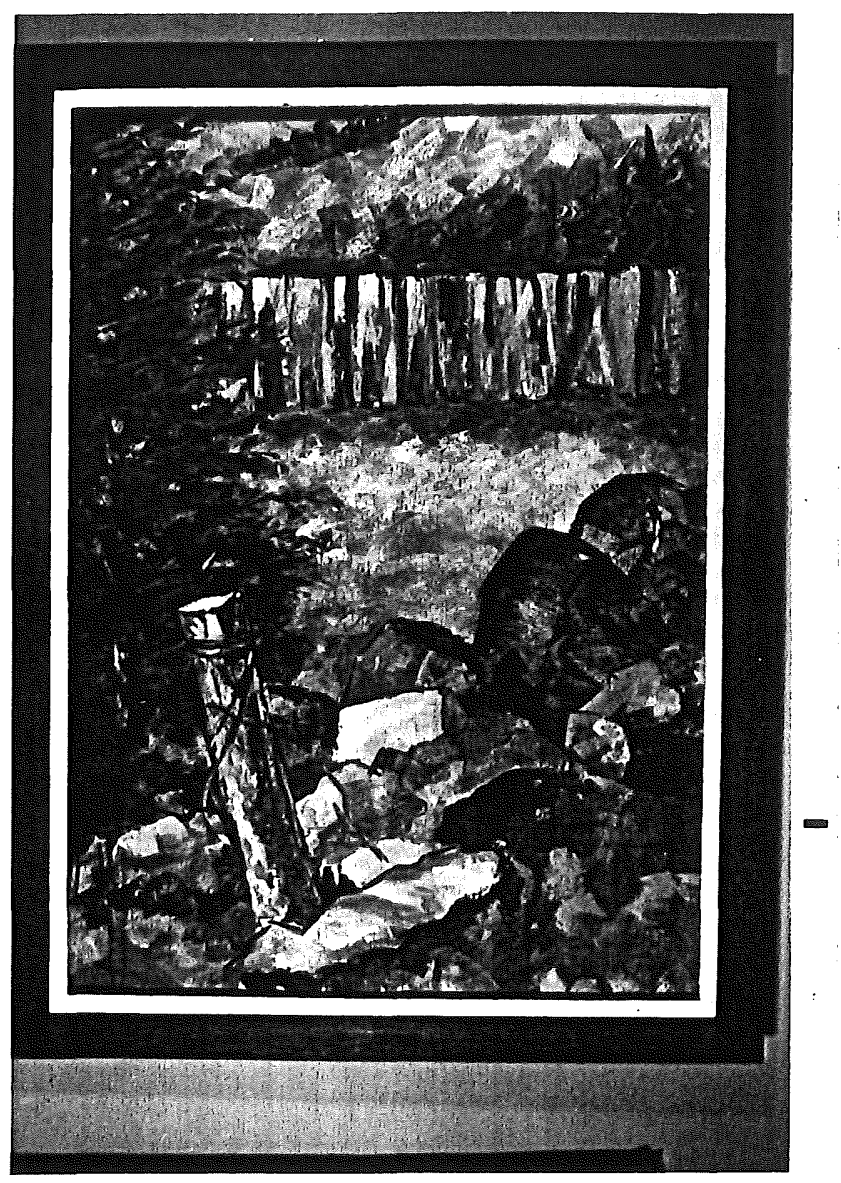

Figure 22, Rock Quarry, Acrylic.

\section{Rock Quarry}

The structural element of strong verticals and horizontals intrigued C'ezanne when he painted from the Bibemus quarry. This painting also utilizes angular shapes of rocks and the quarry walls with their vertical divisions. The upward movement of the verticals contrasts with the horizontal planes. Solid structural shapes are but one element of this composition. Colored pigment dry-brushed over underlying pigment adds to the quality of the color passages. A comparison may be made with the photograph (Figure 21) and the painting. 
Water Fountain

The contrast of value within this composition is pronounced. The figure upon the fountain contrasts sharply with the foliage. The total painting has been effected by the action of light. The shadows turn toward blue and violet; the forms within the sunlight are tinted with a golden yellow. The shadows of the fountain in near foreground turn bluish in contrast to the complementary hue of the sunlit areas. Broken colors prevail throughout; the deep shadows of the foliage behind the fountain seems to flicker due to the controlled breaking of values.

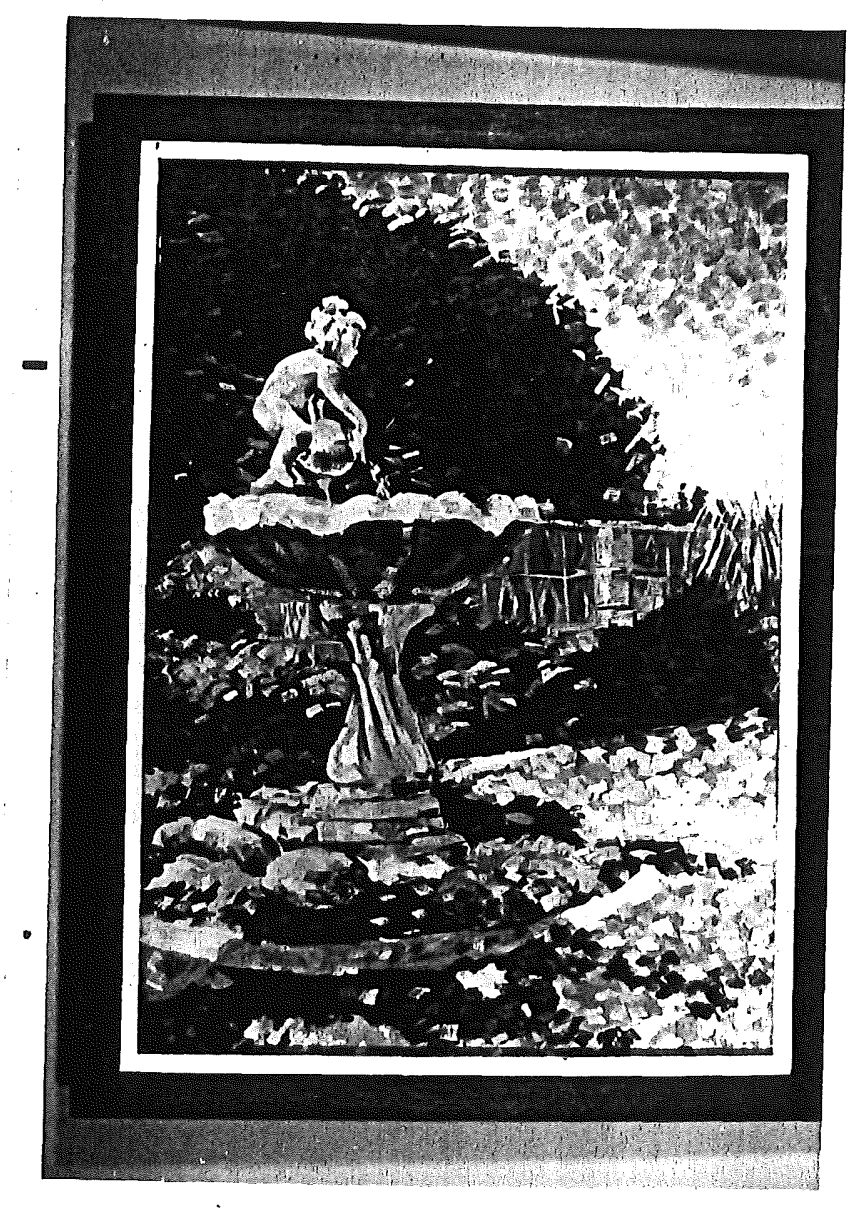

Figure 23. Water Fountain, Acrylic. 


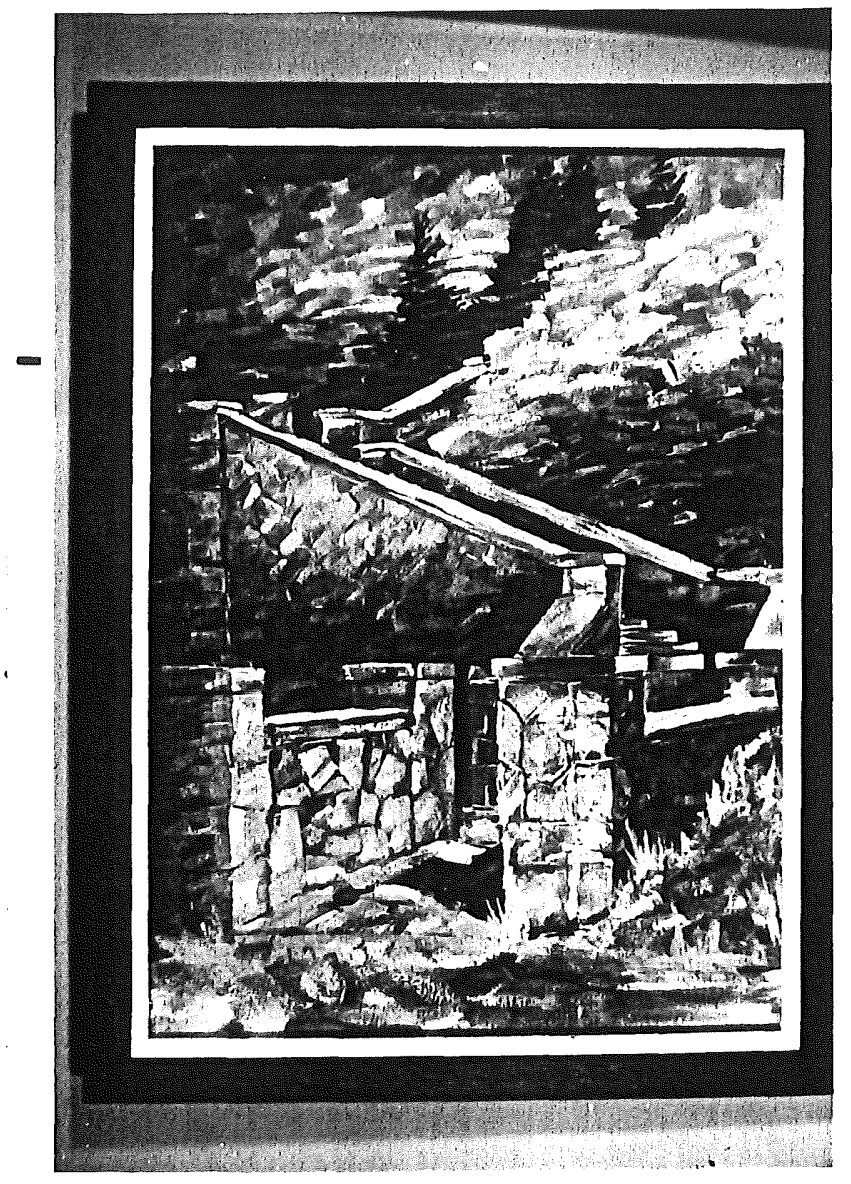

Figure 24. Park Steps, Acrylic.

\section{Park Steps}

The compositional structure of the painting is evident. The walk leaving the near plane, moving first right then up the steps to the left, then right again. This movement holds the composition together. The massive blocks of stone were placed in direct sunlight and take on a yellowish tint, but the shadow areas portray a luninous quality of the complement violet. The juxtaposition of color within areas was accomplished by breaking primarily the values, but other hues were introduced into areas to aid the richness of the color passages. 
Water Wheel

The shimmering quality of water was one of the first subjects to inspire the Impressionists to break color. The ever changing surface of water will cause reflections to change rapidly. The broken surface of a pond will reflect many hues; it will reflect the lighter sky above, the deeper sky at the horizon, plus all elements of the landscape; in this case the old mill and foliage. At times the light rays are reflected equally turning them back into white. We therefore perceive water as an ever changing example of broken color.

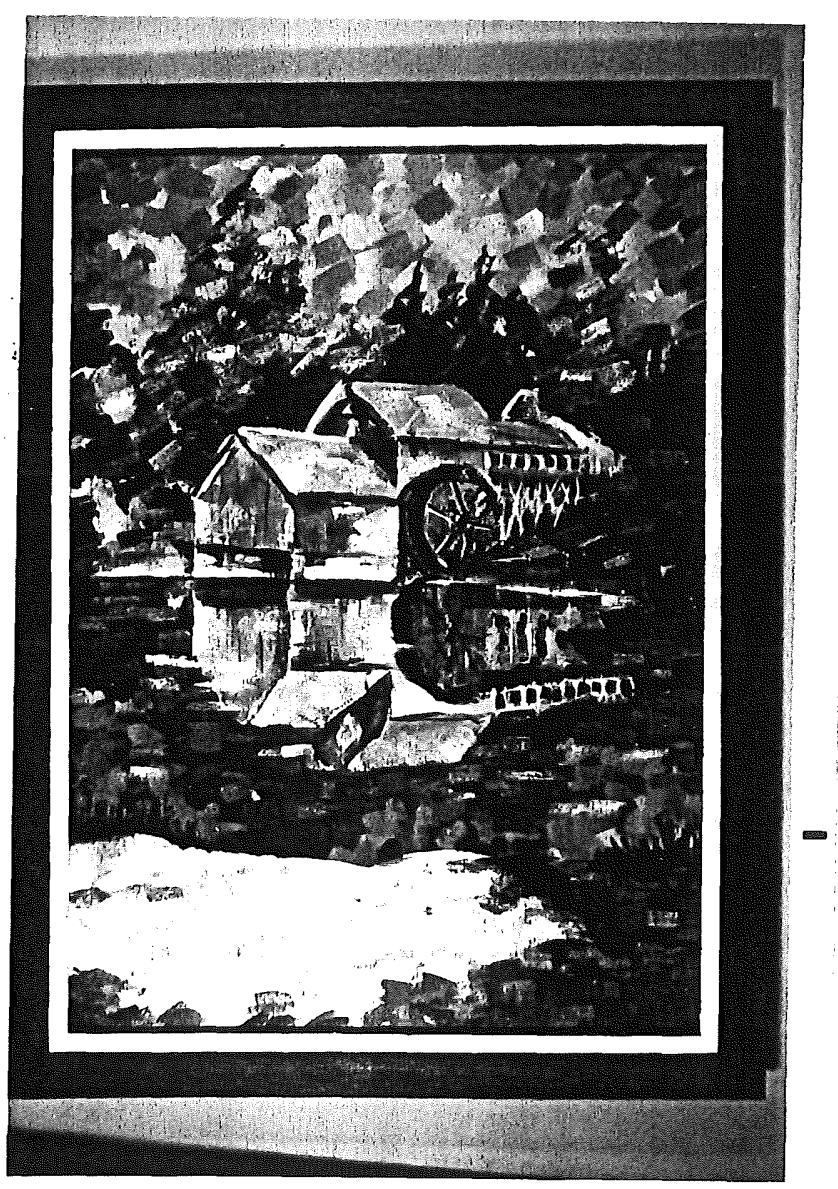

Figure 25. Water Wheel, Acrylic. 


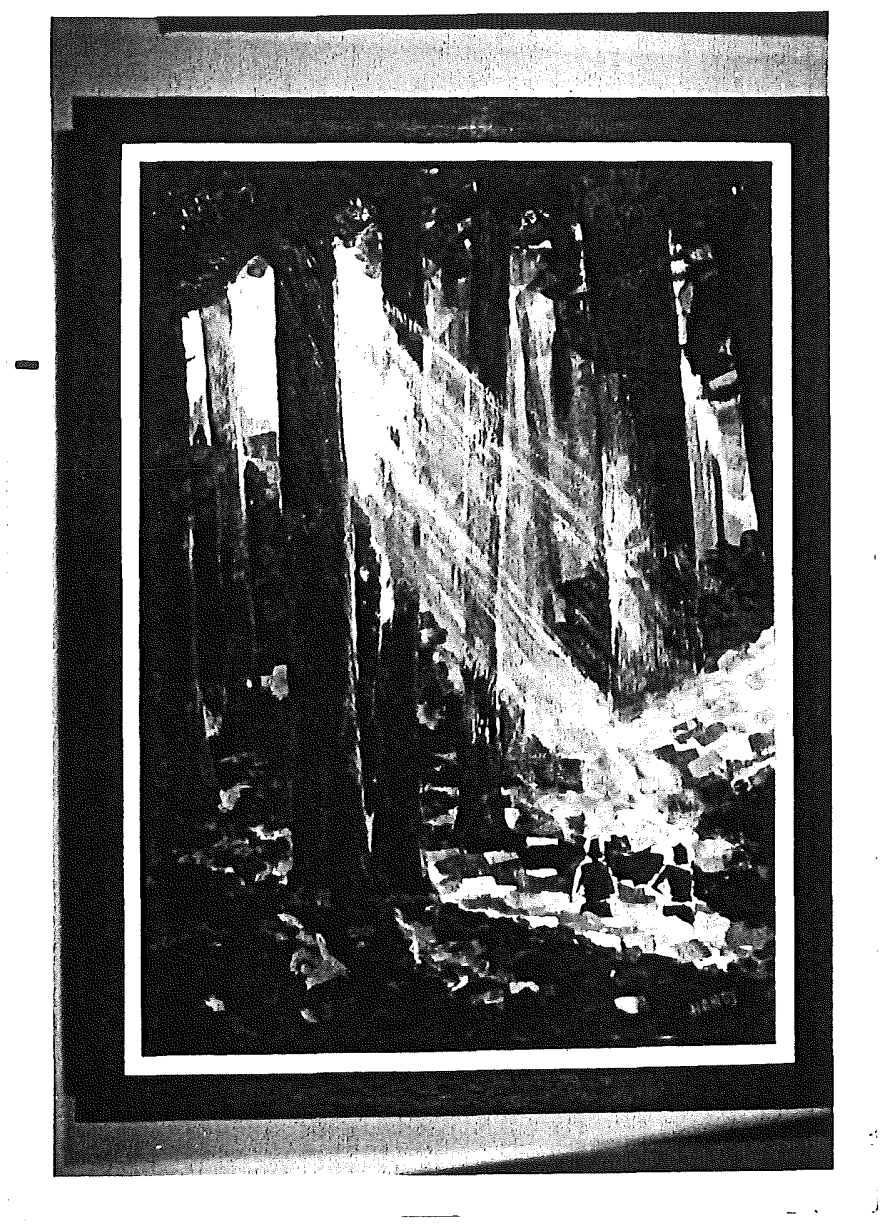

Figure 26. The Redwoods, Acrylic.

The Redwoods

The element of light and shadow within deep forest became the theme of this composition. The tall vertical trees were textured heavily with acrylic modeling paste; then light acrylic glazes were applied over the paste. The foliage within the light areas take on their true local color only to bleach out under strong illumination toward yellow. The foliage under deep shadow turns toward violet and blue. Acrylic jel was added to rays to develop a deep rich transparent light. 
CHAPTER IX

\section{FIGURE STUDIES}

The artist of today as in the past recorded the human figure upon their canvases. Renoir's painting, Nude in the Sun (Figure 27), was painted around 1876 during the full flowering of Impressionism. He painted in terms of the vibration of flesh colors of the model with an interlacing of light and shadow.

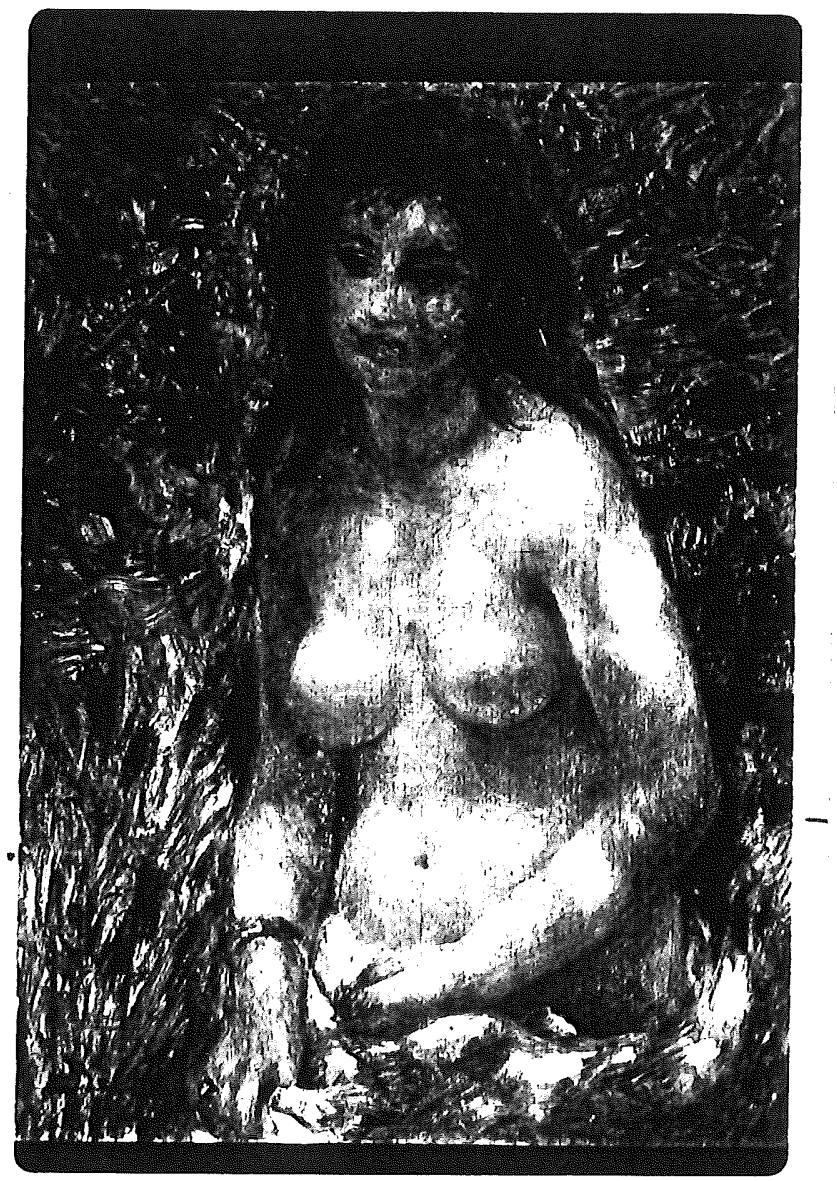

Figure 27. Renoir: Nude in the Sun. 
I. PAINTING

The paintings within this chapter are studies in which the technique of breaking color within the flesh tones of the figure was used. Renoir's flesh tones are a near fusion of small strokes. The strokes within these studies are applied as patches of broad flat strokes and the technique of dry-brushing of pigment over underlying color. There are differences in the range of colors used. Renoir's study (Figure 27) has warm flesh hues with only a suggestion of the cool complementary hues with the shadows. However, the figure studies within the scope of this chapter have a greater range from the cool to the warmer hues. Four studies are presented within this chapter; each to explore the aspects of broken color within figure studies.

Four Nudes

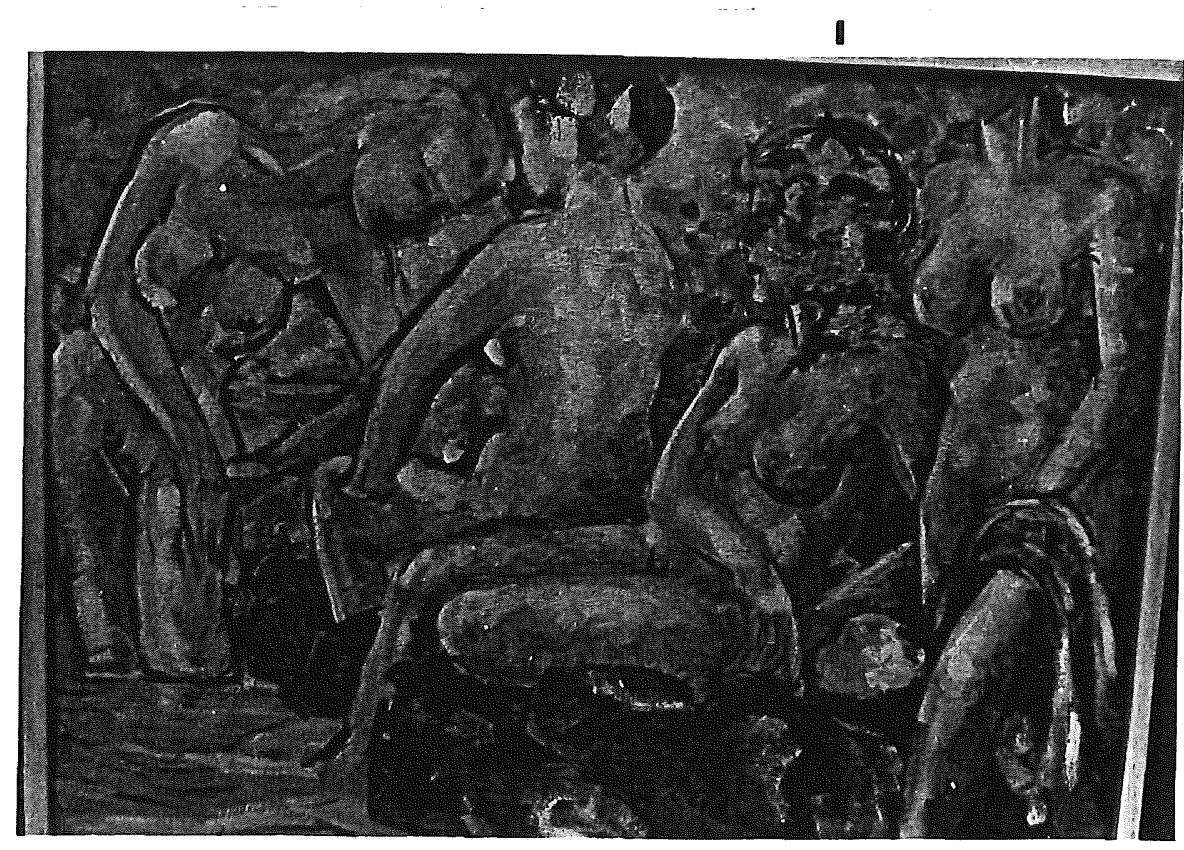

Figure 28. Four Nudes, 28 × 38 inches, Acrylic. 
These four nudes (Figure 28) posed in a natural outdoor setting are flooded with hues of pastel tints. The $\operatorname{cool}$ hues within the shadowed areas are contiguous to the warm light which bathes the figures. The close-up (Figure 29) print visually describes the broken

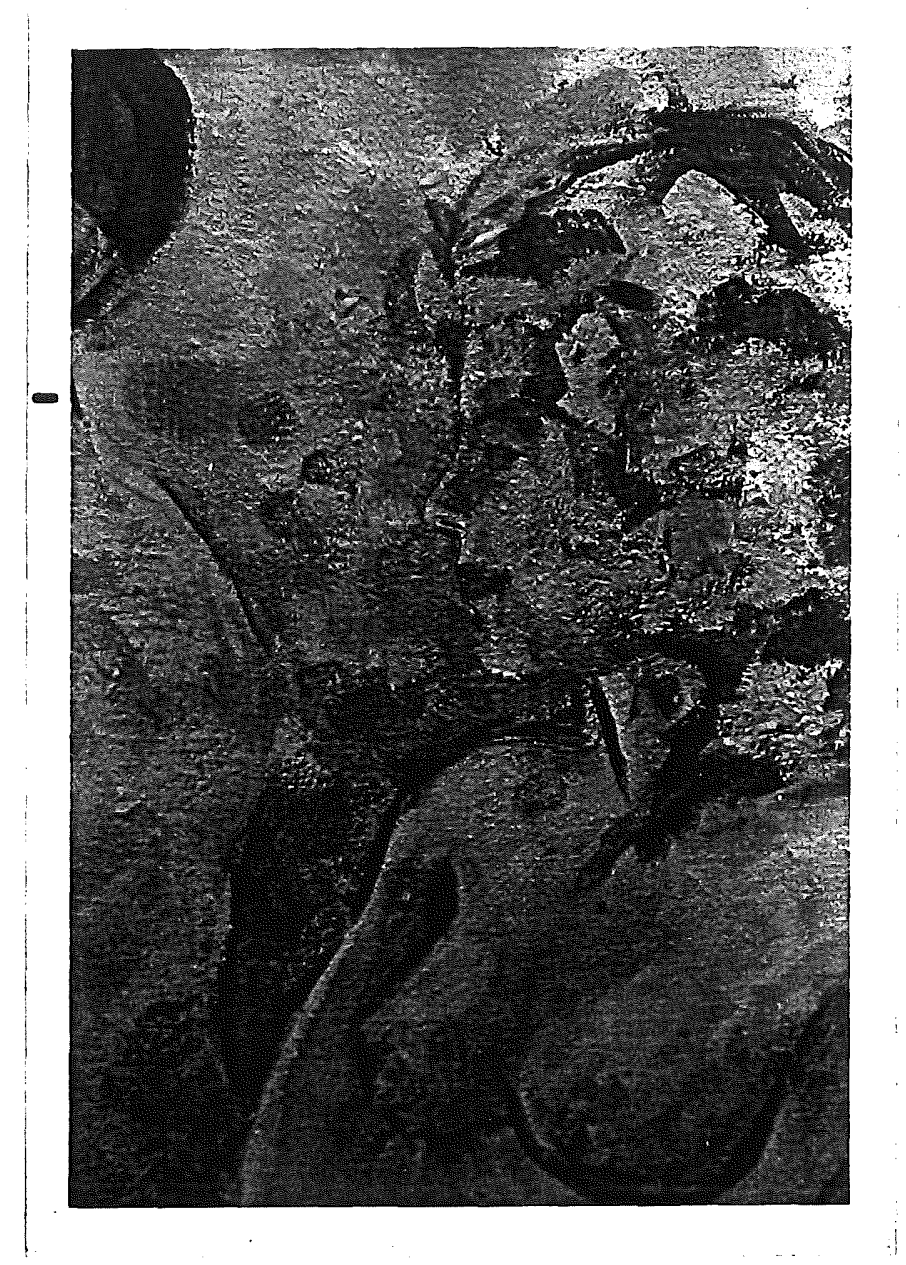

\section{Figure 22. Closemup section of Four Nudes.}

color within the painting. The patches of color are built up over the underpainting by strokes applied in a near dry-brush method. The hue of the under color shimmers through which creates a flickering vibrant surface. Therefore, flesh hues can become lustrous. The luminous surface creates a rhythmic color harmony which unifies the total theme. 
After the Bath

The theme of this study (Figure 30) is a mother drying her son after a bath. The compositional structure of this painting is based upon the traditional triangle of the Renaissance. The mother's body is leaning towards the right and the son to the left. The figures develop form through light and shadow. The shadows flicker with broken values and hues creating areas alive with color. Colors are diffused throughout; the same hues are repeated in all parts of the painting. A yellow tint is observed in the background, figures, and drying towel.

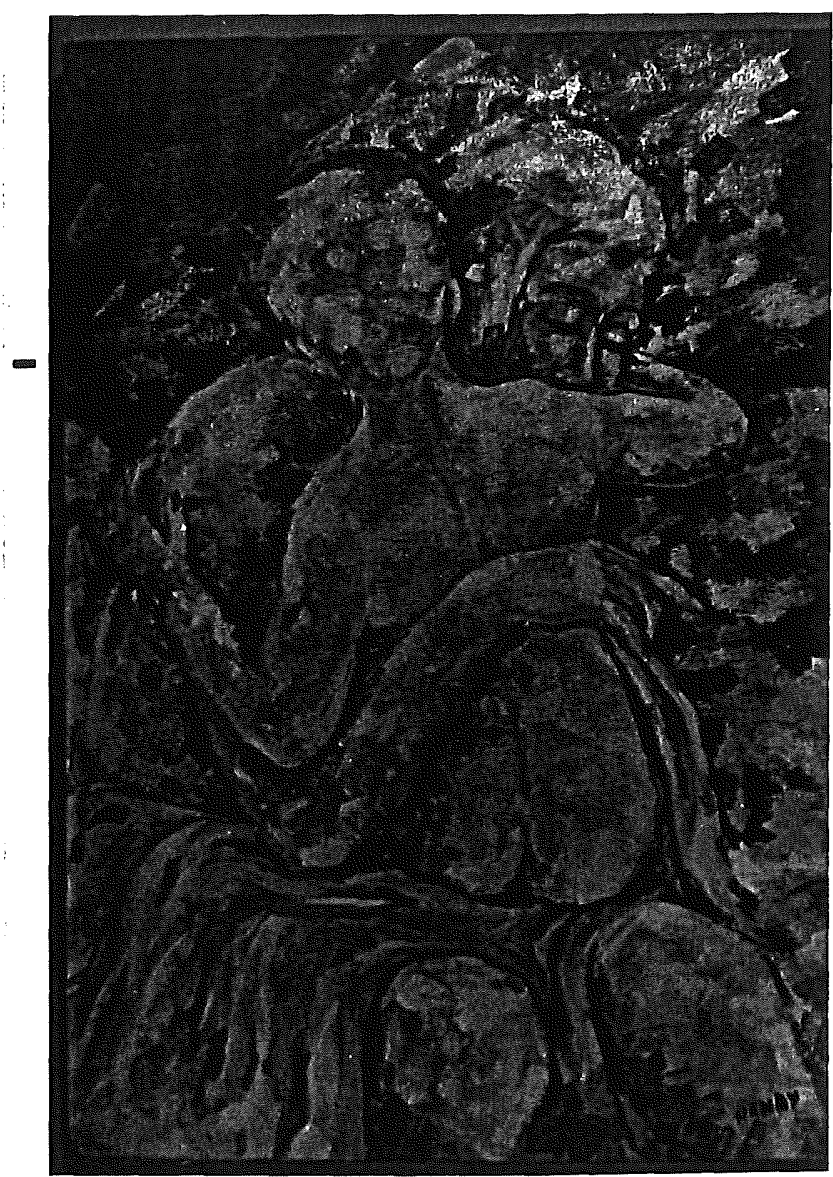

Figure 30. After the Bath, Acrylic. 


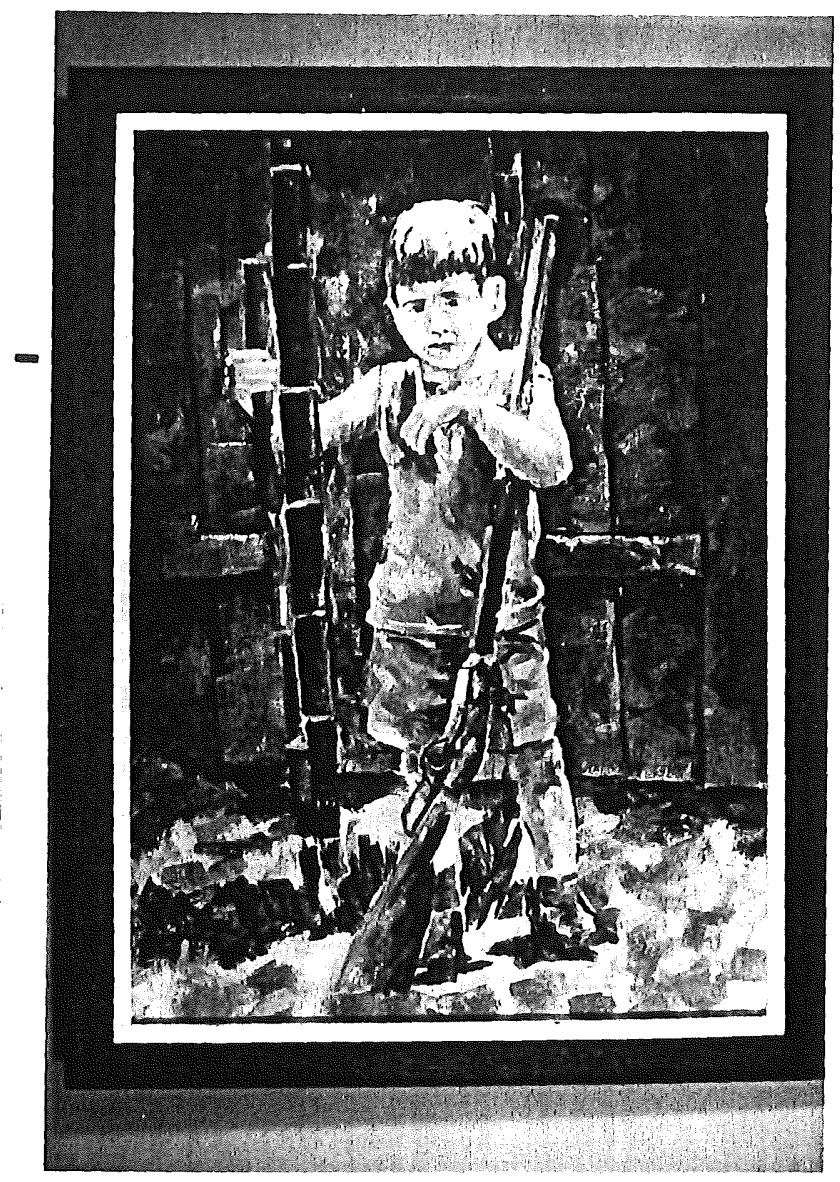

Figure 31. My Son, Acrylic.

\section{My Son}

The subject of a small boy with an old gun standing near a bamboo plant was the motif of the painting. The painting was a study of divided color applied in a direct manner. The grass in the foreground was painted in large patches of color placed over underlying colors in the dry-brush technique. Lighter hues placed over darker hues of the fence creates a shimmering effect by the juxtapostion of hues. The flesh tones became luminous by keeping values light in both cool shadow and in warm light. The total surface is vibrant due to breaking of color. 
At the Table

The approach taken in the painting of young boy at rest was an attempt to freely apply pigment to the canvas in large flat strokes (Figure 32). The simplification of facial planes were painted in direct strokes of warm and cool pigment. This general simplification of all elements of the composition painted in this direct manner aided the total unity of the painting.

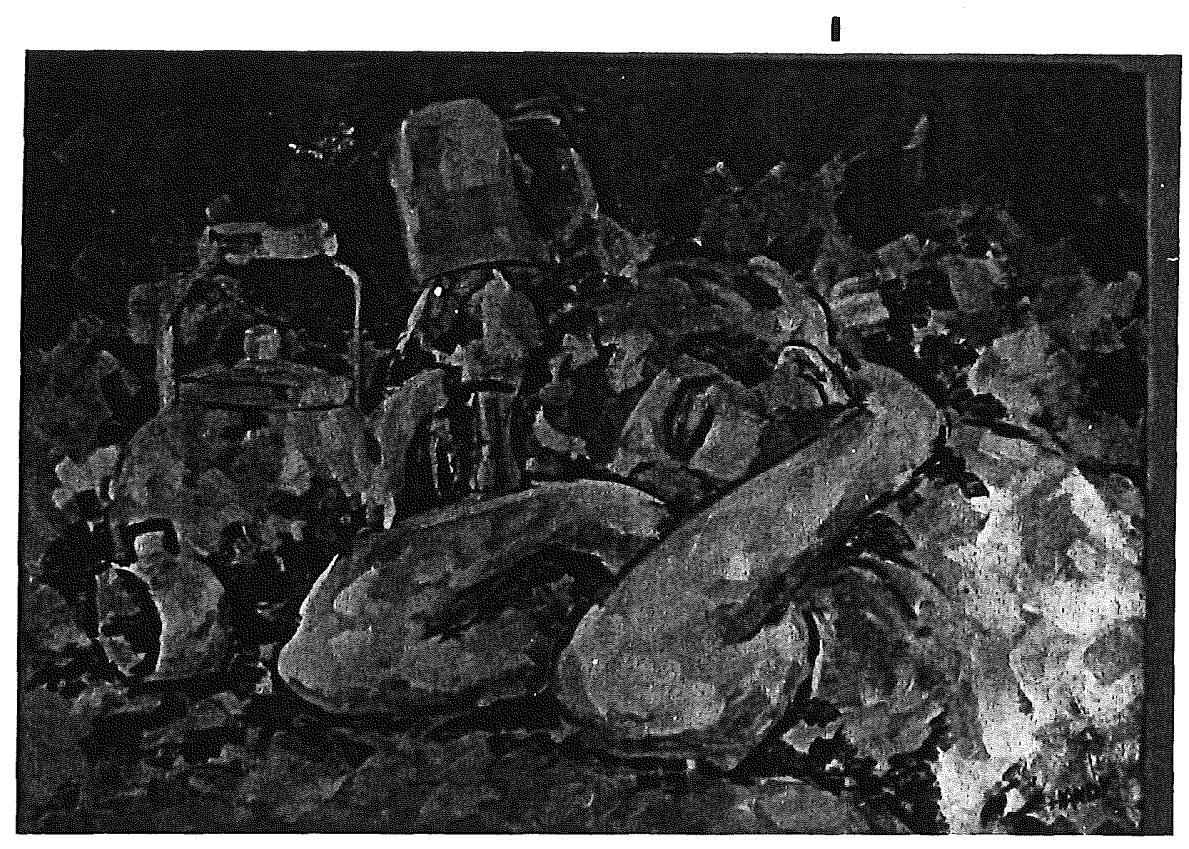

Figure 32. At the Table, Acrylic.

\section{SUMMARY}

The figure studies were directed towards exploring the aspects of color as applied to the canvas with direct strokes leaving no blending upon the surface of the canvas. This painting style creates a surface quality rich with divided color. 
CHAPTER $X$

\section{ADOLESCENT PAINTING}

An application of the broken color methods was introduced within several ninth-grade elective painting classes with an emphasis to create within each student a visual awareness of the richness of broken color.

\section{THE ADOLESCENT ART STUDENT}

The adolescent student is living in the in-between age. He is not a child and not an adult either. This creates not only a problem for him but a challenge to the educator as well. The ninth-grade student is nearing adulthood and is eager and ready to explore most any activity. This is a novel period in their lives, almost everything in the arts is new and interesting to the adolescent.

The ninth-grade art student has approached a point in his development in that he has reached a higher point of maturity than his younger peers in several ways.

\section{Self Awareness}

Within the serenth and eighth grades a student is usually satisfied with just the completion of an assignment. The ninth grader becomes more self conscious, more critical, and more aware of the quality of their work. The student begins to compare the quality of his art with adult standards. To assure each person a degree of success, art education must be directed towards the individual and not the group. 


\section{Attention Span}

At this age the attention span can be concentrated on one problem for a much longer period than at any previous time in their lives. the student begins to study and solve problems within his work.

\section{Communication}

The adolescent has entered an age where he and the teacher may more fully communicate. By being able to relate to one another at a more adult level the young adult will progress much in the arts; he will more fully realize the nature of most any assignment.

\section{THE PAINTING PROGRAM}

The major premise of this research was to explore the broken color and apply ramifications of divided color within painting experiences of the adolescent student. The direction taken in the adolescent painting program and the results thereof will culminate this research.

\section{Preparatory Methods}

The application of this research must be presented in a well organized painting program and must operate within the educational structure. It must conform to indoor classroom situations such as length of class, class size, lighting, and supplies.

Student Preparation. Before undertaking painting, the student's program contained units in drawing and shading, perspective, design and composition, and color mixing.

The Preparation of Supplies. (Figure 33) Organization was the most important factor for the success of the painting program. All 
supplies, the easels, oils, brushes, palettes, rags, and turpentine were always ready for the students. The boards for the strectcher frames were brought from home and assembled and canvas stretched by the student within the classroom. This new experience inspired motivation within the student.

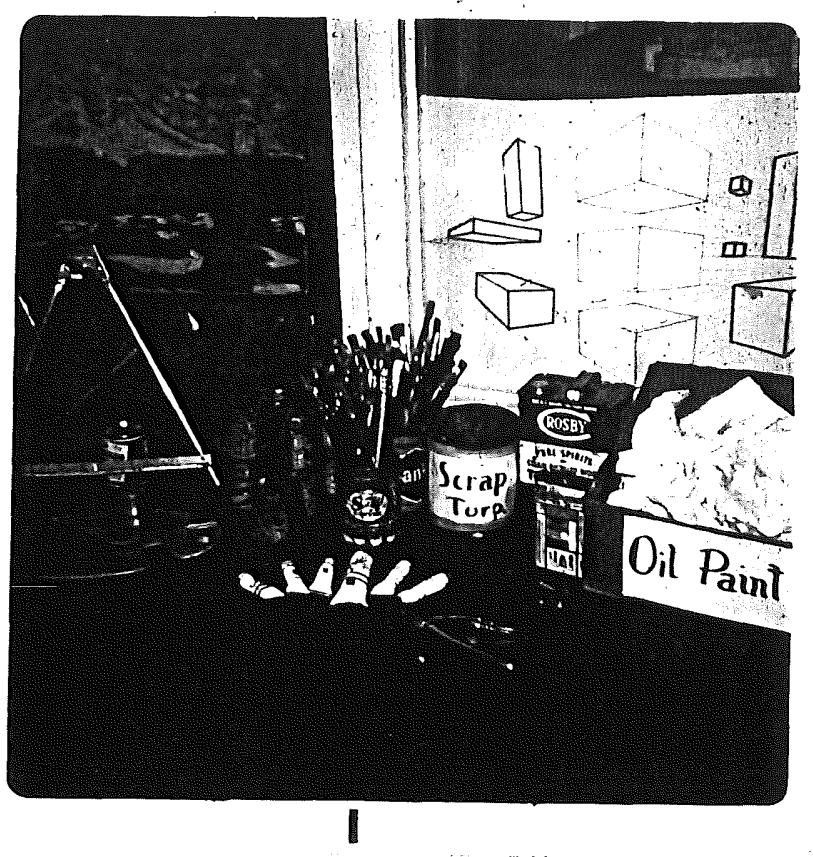

Figure 33. Painting Supplies.

Subject Matter Preparation. To compensate for indoor painting and lighting, solid still life boxes were assembled. Due to the Impressionist concern about light conditions, each box contained an electric spot to keep the light constant and the development of form through light and dark.

\section{THE SUBJECT OF THE PAINTINGS}

The subjects of the paintings were still life, landscape, and 
seascapes.

Still life. (Figure 34) Still life arrangements were used as the subject for the first study utilizing the divided color technique by the adolescent student. Still life offers an excellent opportunity to first study drawing and composition with the close inspection of color with all extraneous reflections. The objects selected for the arrangements were simple and geometric in shape and vary in size, shape, and texture. The compositional arrangements were made in the grouping by color harmonies and contrasting light against dark.

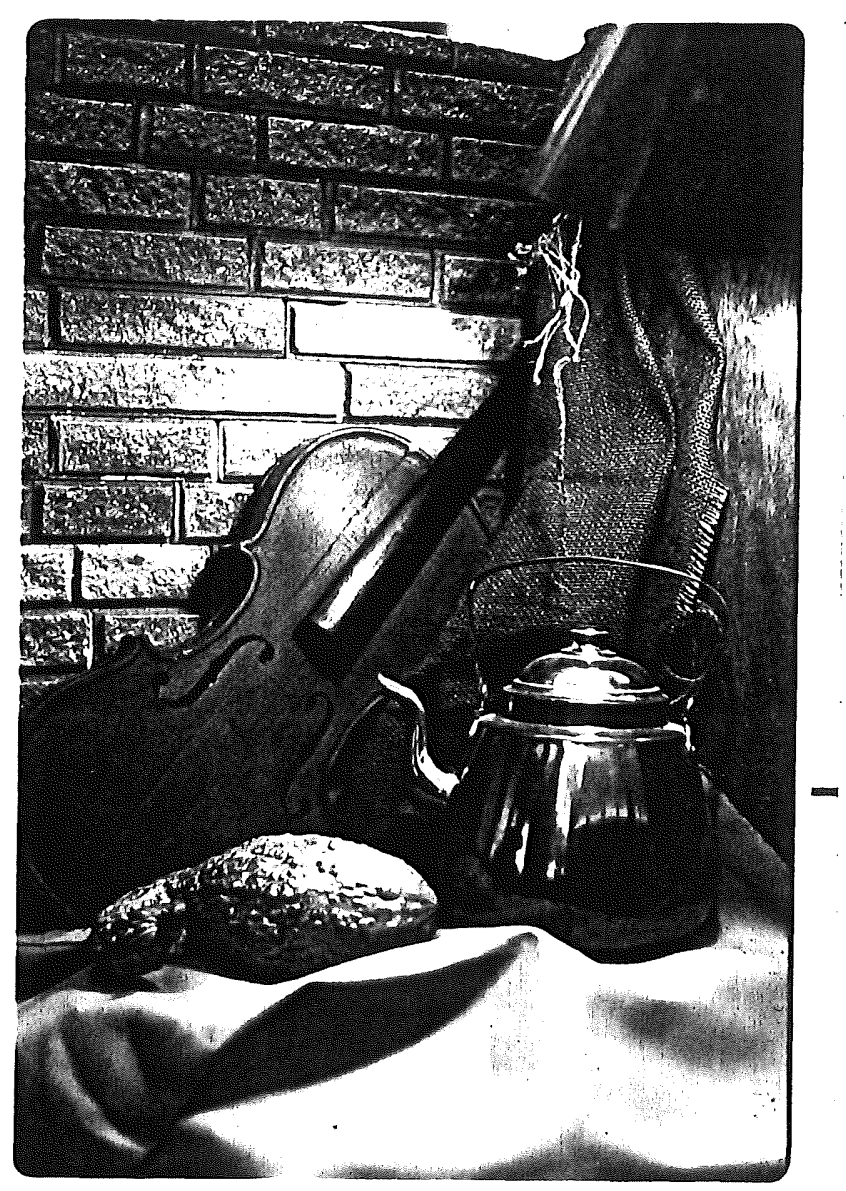

Figure 34. Still Iife Study. 
Landscape. The application of the divided brush technique within landscape must be done in the framework of school routine. Small landscape studies may be made by the student at the site; however, in all probablity, the final painting must be done in the classroom. The young boy (Figure 35) is utilizing a slide projector to aid him as he paints.

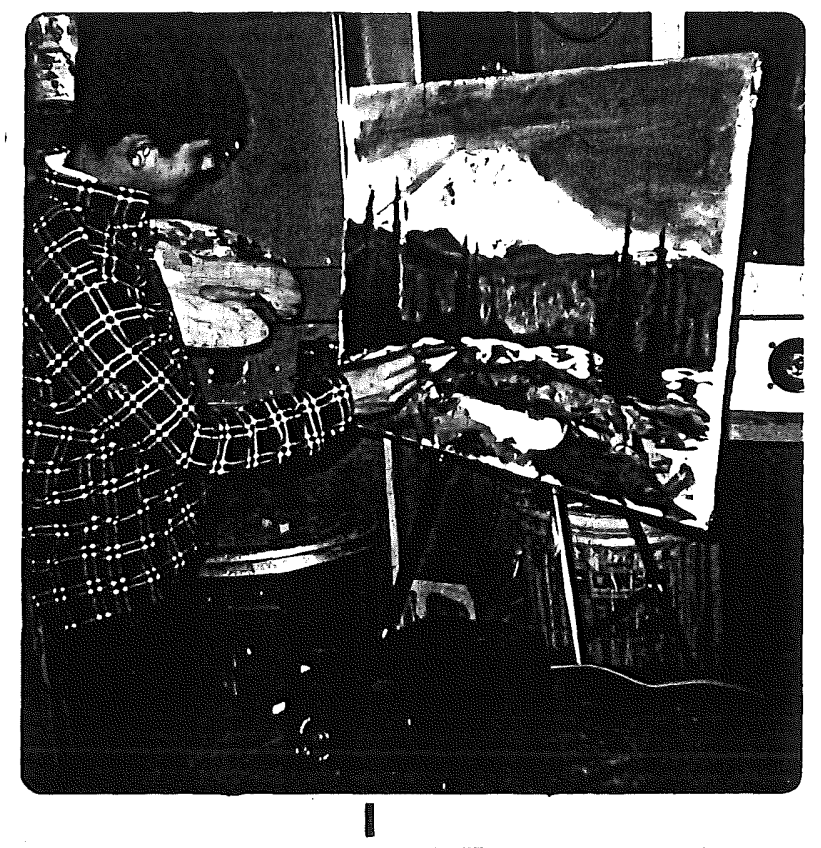

Figure 35. Landscape Study.

Seascape. The sea became the subject of this young boy in his painting (Figure 36). He was encouraged to explore the effects of divided color within his painting. He selected an impasto effect to break surface colors and to aid in capturing the action of the scene. Thick modeling paste was applied by the use of a trowel (Figure 37) and a palette knife. The colored pigment was then applied over the textured modeling paste creating a dimensional quality to the 
seascape.

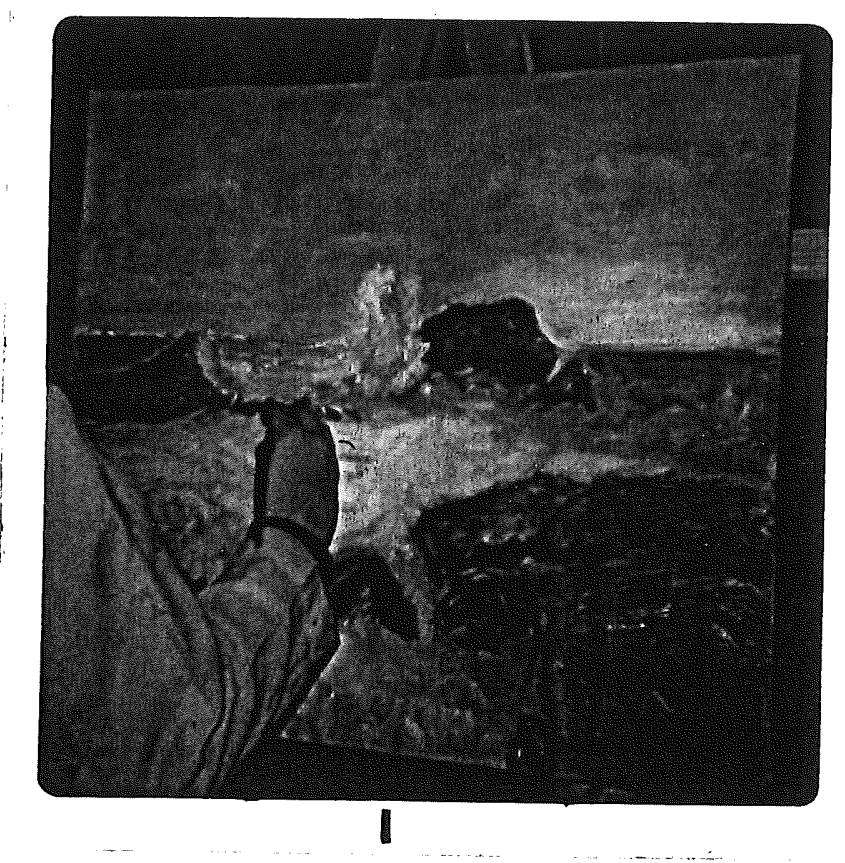

Figure 36. Seascape Study.

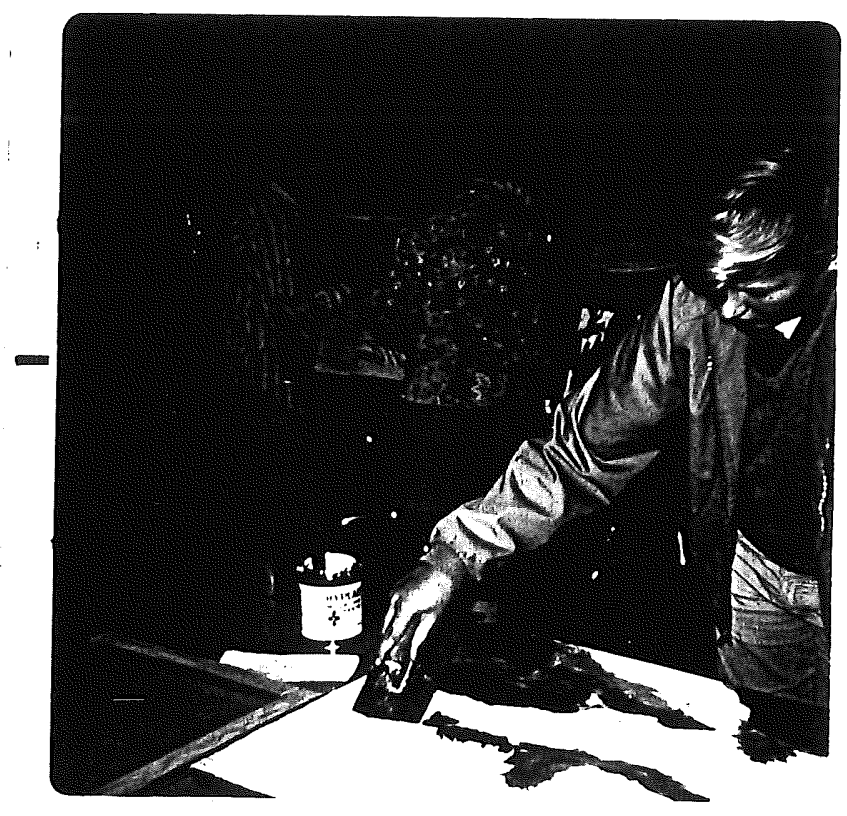

Figure 32. Application of Paste. 
IV. CLASSROOM MEDIA

The media used in the program were varied in an attempt to more fully explore the divided color effects within adolescent painting.

$\underline{0 i 1}$

The medium used for most paintings was oil. When many students are painting within hour time periods, oil has an advantage over other media. A student may use a palette for one class and a student from the following class may use the same palette with little problems.

The use of oil in the divided color technique should be applied without mixing on the canvas; therefore, the underlying pigment should be semi-dry to keep the additional pigment from muddying the hues. By painting daily with oils on the canvas, the hours between one day to the next will give the oil a chance to partially dry providing it has not been applied heavily.

Acrylic

Acrylic paint is the better media to create broken color effects. The speed of drying allows the painter to apply new pigment over the underlying areas without blending. Acrylic may be dragged over the underlying color in the technique of dry-brush and the underlying hues will shimmer through. It also may be applied in thin watered-down pigment in transparent patches overlaided one over another. 
The disadvantages of mass use of acrylics within the structure of the classroom are the cost factor and the clean-up problem. When acrylic pigment is placed upon the palette, it must be used. However, a limited use of acrylic was utilized within the adolescent painting program.

\section{Other Media}

The broken color method of pigment application was also explored within watercolor, tempera, and encaustic painting. Each has, like acrylic, the advantage of rapid drying. But unlike acrylic, the pigments have a tendency to muddy and blend with neighboring hues. Encaustic was effective as an individual experience. The heated colored wax would cool rapidly when applied leaving a surface rich with broken patches of color. 
CHAPTER XI

SUMMARY AND CONCLUSIONS

I. SUMMARY

The painterly direction within art reached new heights during the short span of the Impressionists. The liberties taken helped clear the road taken by the contemporary artists of today. The NeoImpressionist's scientific approach dealt with optical perception which effected certain aspects of painting today. The artists contemporary with artists of that time who were inadvertently effected were Van Gogh, Cauguin, Cézanne and many others. They, in turn, influenced the artists of today.

The painting within the scope of this research was directed to this era in painting due to the painterly mode of their style and to apply ramifications of divided color within the painting classes of the young adult.

\section{CONCLUSIONS}

One of the major aims of an art educator is to present experiences in which the students may become more aware of the richness of visual sensations. Many people today can see but are the walking blind, unaware of all the beauty confronting them. The Impressionist saw nature as colored light and set about to paint his visual sensations. Students do not see in this manner, they are conditioned to 
draw outlines and fill in the forms with flat unmodeled color. Through experiences in divided color, most students should develop an awareness of the aspects of the rich textured quality of broken color.

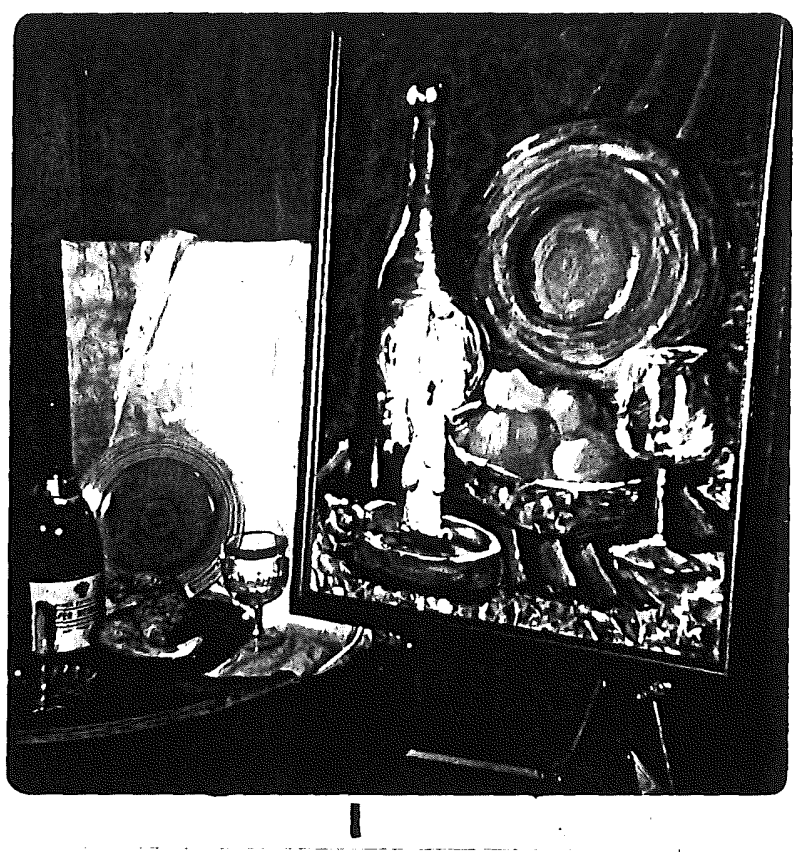

Figure 38, Student Painting Display.

A young artist's painting (Figure 38) is a visual conclusion of this research. The painting is placed by the still life from which it was painted. On close inspection (Figure 39) the surface planes have been broken with many divided strokes of a brush creating a flickering surface in the place of a dark flat background. Broken color has added another dimension within the visual experience of this adolescent student.

Within the technology of our contemporary world, man may at some future date, present the artist with new vibrant pigments which will add new dimensions in capturing the effect of light upon the surface of 
a canvas.

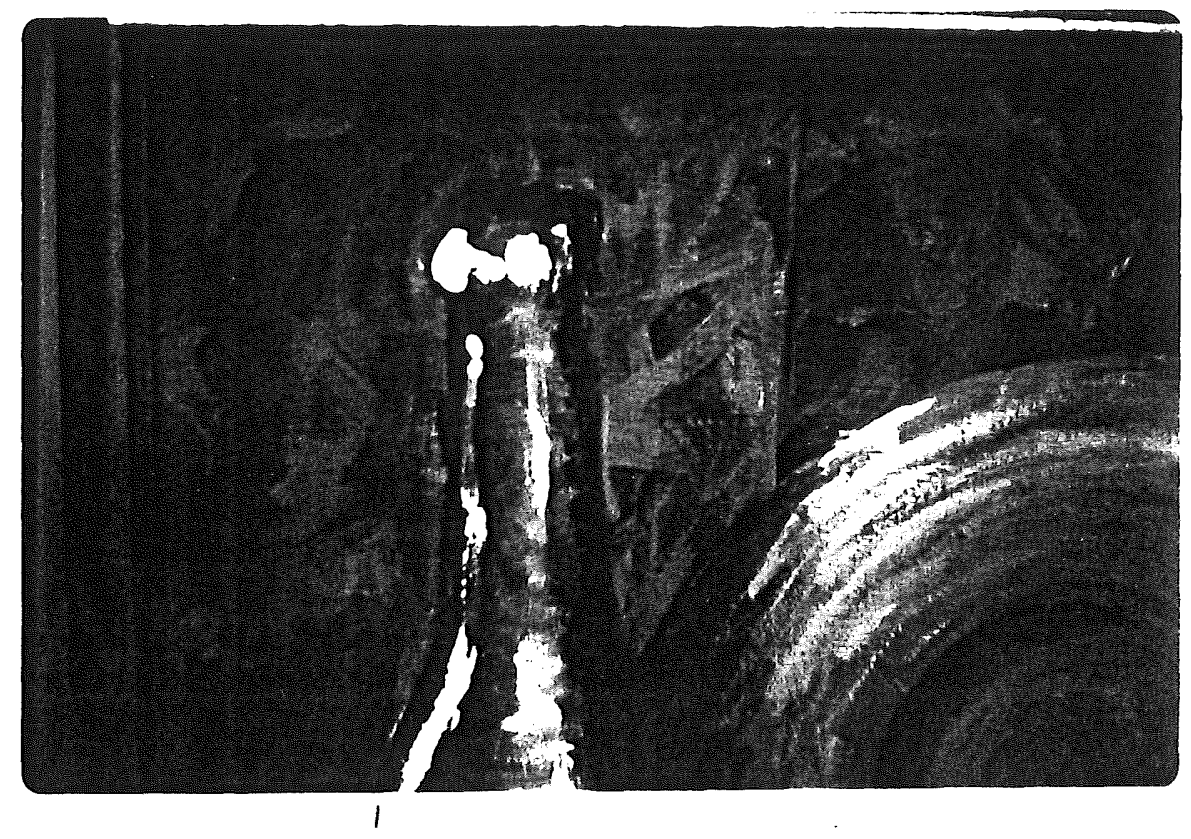

Figure 39. Example of Broken Color. 


\section{A SELECTED BIBLIOGRAPHY}

Birren, Faber. Creative Color. Now Yorks Reinhold, 1961

History of Color in Painting. New York: Reinhold, 1965.

Brown, Richard. "Impressionist Techniques Pissarro's Optical Mixture." Magazine of Art, January, 1966, pp. 12-15.

Canaday, John. Mainstreams of Modern Art. New Yorks Holt, Rinehart and Winston, 1965.

Chevreul, Michel Eugene. The Principles of Harmony and Contrast of Colors. New York: Reinhold, 1967.

Color Digest. New York: Higgins Ink Co.. 1965.

Fabri, Ralph. Color - A Complete Guide for Artist. New York: WatsonGuptill Publications, 1967. Publications, 1969.

Gardner, Helen. Art Through the Ages. 4th ed, New York: Harcourt, Brace and Company, 1959.

Graves, Maitland. The Art of Color and Design. 3rd ed. York, Pa.: Maple Press Co., 1951.

$\longrightarrow$ Color Fundamentals. New York: McGraw, 1952.

Gutiérrez, José, and Roukes, Nicholas, Painting with Acrylics. New York: Watson-Guptill Publications, 1966.

Hansen, Lawrence, and Hansen, Elisabeth. Impressionism Golden Decade. New York: Holt, Rinehart and Winston, 1961.

Homer, William, Seurat and the Science of Painting, Cambridge, Mass.: M.I.T. Press,1964.

Itten, Johannes. The Art of Color. New Yorks Reinhold Publishing Co., 1961.

Jansen, H. W. History of Art. Now Yorks Abrams Inc.. 1963.

Logan, Fredrick. Growth of Art in American Schools. New York: Harper and Brothers Publishers, 1955.

Loran, Erle. Cézanne's Compositions. Berkley, Californias University of California Press, 1943. 
Lowenfeld, Viktor. Creative and Mental Growth. 3rd ed, New York: The Macmillan Company. 1957.

Pellew, John. Acrylic Landscape Painting. New York: Watson-Guptill Publications, 1968.

Pope, Arthur. The Language of Drawing and Painting. Cambridge, Mass.: Harvard University Press, 1929.

Rewald, John. Post Impressionism. New York: Museum of Modern Art, 1956. Art, 1961.

Rood, Roland. Color and Light in Painting. New Yorks Columbia University Press, 1941.

Serullaz, Maurice. Impressionist Painters. New York: Universal Book Ine. 1960.

Stone, Joseph. "The Art of Impressionism." Arts Yearbook. New Yorks Arts Digest Inc., 1958.

Woody, Russell. Painting with Synthotic Media. New York: Reinhold Book Corporation, 1969. 